\title{
Fly ash-based geopolymers: an emerging sustainable solution for heavy metal remediation from aqueous medium
}

\author{
Piyush Gupta 1*(D), Garima Nagpal ${ }^{2}$ and Namrata Gupta ${ }^{3}$
}

\begin{abstract}
Background: The water supplies are hindered because aquatic resources have constrained with natural and manmade pollution activities in terms of releasing huge amounts of contaminants from different point and non-point sources across the globe. The industries like metal plating, batteries, paint, fertilizers, tanneries, textile industries, dyeing industries, mining operations, and paper industries discharge their effluents into the environment directly or indirectly, and hence, they are considered as the key sources of heavy metals contamination in water resources. Heavy metals are inorganic, non-biodegradable, persistent, and having a tendency to get accumulated in biotic and abiotic components of environment as compared to organic pollutants. Some heavy metal cations, for example, mercury, arsenic, cadmium, zinc, lead, nickel, copper, and chromium, are carcinogenic in nature and so, lethal. There are growing health concerns due to toxic impacts of heavy metals on every genre of ecosystem. To deal with the bottleneck situation, it is highly imperative to search a feasible solution for heavy metal remediation in water in context of preventing amalgamation of noxious contaminants in food web. Different methods are exercised for the remediation of such impurities from its solutions. One method, i.e. adsorption is found to be the simplest, economical, efficient, and eco-friendly in this context.

Main body: Geopolymers exhibit heterogeneous amorphous microstructure and wide surface area. The compatibility for depollution and the performance of these materials mainly depend upon their preparation methods, composition, and microstructure. Fly ash-based geopolymer may serve as a better alternate to various cost-effective adsorbents and it will be a proven environmentally viable, waste to money solution by consuming heaps of fly ash waste for the adsorbent modified by using fly ash. The possible utilization of wastes from several industries is a matter of concerned sustainability benefits. This study shows that fly ash-based geopolymers have the potential to cope up with the problems and risk factors associated with the fly ash waste management and it would be the utmost scientific panacea in the field of removing toxins from aqueous medium and maintain environmental health in the future.

Short conclusions: The literature available in different databases is very limited pertaining to heavy metal remediation using fly ash-based geopolymers. Keeping all the factors in mind, this article is an attempt to summarize relevant informations related to work done on fly ash-based geopolymers for treating aqueous solutions comprising heavy metals.
\end{abstract}

\footnotetext{
*Correspondence: piyushg.1977@gmail.com

${ }^{1}$ Department of Chemistry, Faculty of Engineering and Technology, SRM Institute of Science and Technology, NCR Campus, Delhi-NCR Campus, Delhi-Meerut Road, Modinagar, Ghaziabad, Uttar Pradesh 201204, India Full list of author information is available at the end of the article
} 
Keywords: Fly ash, Geopolymers, Fly ash-based geopolymers, Aqueous medium, Contamination, Heavy metals, Adsorption, Adsorbents

\section{Background}

The universal solvent water is a fundamental need for the survival of biotic and abiotic components of the ecosystem on earth. Rapid industrialization and developmental activities have accumulated various substances like heavy metals, dyes, paints, and pigments, surfactants, pharmaceuticals, pesticides, personal care products, etc. in water reservoirs and adversely affected the clean water supplies. The effluents discharged from paper, plastics, textile, tannery, steel, metallurgy, electroplating, dyes and dyeing, petroleum, and battery industries are the chief sources of water pollution [1]. Heavy metals beyond the maximum permissible limits are detrimental to flora and fauna due to its toxic nature and bio-accumulation [2,3]. The excessive amounts of toxic heavy metals, i.e. lead, arsenic, chromium, mercury, cadmium, nickel, zinc, cobalt, manganese, copper, molybdenum, etc. in water attack on nervous system, damage to liver as well as kidney, and other prominent diseases $[4,5]$. Arsenic toxicity causes skin lesions leading to hyperkeratosis, vomiting, abdominal pain, muscle cramps, skin cancer, change in pigmentation and may be death in some extreme cases [6]. Chromium is a carcinogen and genotoxic in nature and it affects via inhalation route, causing lung and respiratory tract cancer [7]. Moderate concentration of copper causes gastrointestinal problems, higher concentrations of $\mathrm{Cu}$ cause Wilson disease and several other disorders in human body. It may lead to increase taste problems and liver damage $[4,8]$. Antimony is also carcinogenic in nature. Lead damages the neurological system and disrupts vitamin D and calcium metabolism. [9]. Lead can cause loss of appetite, constipation, slurred speech, impaired consciousness, and brain damage $[5,10]$. Excess manganese in drinking water can cause weakness, fatigue, hallucinations, and severe neurological disorders [11]. Methyl mercury makes the skin pink in children and sometimes peels out the skin. Mercury causes Minamata disease that affects kidneys, nervous systems, colitis and haemorrhagic gastritis [12]. Molybdenum is deadly poisonous for bottle feeding new-borns [13]. Nickel is responsible to cause dermatitis and cancer [14]. Selenium poisoning is not good for nails, hair, and liver health [15]. Cadmium is carcinogenic in inhalation, damages kidney and liver, retards growth, causes anaemia, itai-itai disease, chronic obstructive lung disease (pulmonary oedema) and renal arterial hypertension. Cobalt may cause vomiting, loss of hunger, ear ringing, and enlarges the thyroid gland [16].

A large number of methods like floatation, filtration, flocculation, coagulation, chemical precipitation, microbial system, advanced oxidation process, ion exchange, reverse osmosis, electrodialysis, electrochemical process, desalination, adsorption, evaporative recovery, supercritical fluid extraction, and membrane bioreactors have been used for removing contamination from wastewater with their own strengths and drawbacks [17-24]. Efficacy, economic viability, and environmental friendliness screen the usage of some conventional techniques and draw the attention of researchers to explore the adsorption as a simple, effective, and economical procedure [25-29].

A number of variety of adsorbents like natural clays, natural and synthetic zeolites, activated carbon, biomass derived activated carbon, resins, chitosan, agricultural wastes, industrial by-products, carbon-based materials, nanomaterials, hydrogels, nanoparticles, nanocomposites, spinel ferrite magnetic materials, etc. were used for wastewater treatment. The expensive synthetic procedures and difficult regeneration set these adsorbents back in large-scale wastewater treatment [30-54].

Since high surface area, porous structure, durability, easy regeneration, biodegradability are the basic requirements of a good adsorbent for significant decontamination, therefore, to deal with the limitations of the above-stated adsorbents, an extensive list of sequential naturally occurring, synthesized, and waste products with high removal efficiencies has been used as adsorbents. One of the waste products of thermal power plants is fly ash; fly ash is generated by coal-ignited electric and steam producing plants as a by-product. It is usually stockpiled at thermal power plants or disposed of in landfills. Nowadays, it is used in hydraulic cement and concrete production. The substantial need of the hour is to recycle the waste materials and convert them into economically feasible valuable materials for future applications.

Due to chemical composition and recycling of this waste material collected from electricity generating thermal power plants, several researchers are seeing fly ash as viable future solid raw component for separating contaminants in commercial wastewater treatment. It is a low-cost aluminosilicate source to produce effective microporous adsorbents like zeolites. The best approach to consume fly ash waste is the modification of fly ash 
into an effective geopolymeric material in heavy metal remediation and other water contaminants [55-67]. The current and emerging environmental applications present geopolymers as a

- Binder, sustainable repair material due to its low shrinkage and high resistance to thawing and freezing, composites for infrastructures repair and strengthening,

- Construction material (potential substitute of Portland cement), cements and concretes,

- Carbon capture material owing to its good acid resistance, high mechanical strength, durability and low permeability,

- Resins for coating material,

- Ceramic material,

- Decorative stone artefacts,

- Sealing material for toxic waste residues from industries, radioactive and toxic waste containment, waste encapsulation,

- Mitigation component for pollution and climate change related issues,

- Bio-technologies (materials for medicinal applications), drug delivery carrier,

- Fire-resistant materials, thermal insulation, foams,

- Thermal shock refractories (thermal insulation),

- High-tech lightweight carbon fibre composite materials used inside and outside of aircraft,

- High-tech composites for automobiles,

- Environmentally friendly adhesive for wood-based panels and modern biotechnology, and

- Dielectric materials for electronic packaging and molecular sieve catalysts material.

Geopolymer comprises a polymeric silicon $(\mathrm{Si})$-oxygen $(\mathrm{O})$-aluminium ( $\mathrm{Al}$ ) three-dimensional network with alternating $\mathrm{Al}$ and $\mathrm{Si}$ tetrahedral attached altogether by sharing all oxygen atoms as similar to zeolites. The key specification of geopolymers over zeolites is the amorphous structure instead of crystalline [68, 69].The availability of literature in this research domain is very small and comprehensive reviews on heavy metal removal using fly ash-based geopolymeric adsorbents are very limited. Thus, our study reviews the fundamental conceptual model for designing geopolymers with their characterization and the potential exploration of fly ash-based geopolymers in heavy metal remediation like arsenic, copper, lead, zinc, nickel, chromium, caesium, magnesium, cobalt, cadmium, ammonium, etc. from solutions. The structural modification provides a more number of accessible sites by inducing the creation of open-framework like structure which can store a large amount of heavy metal cations via adsorption from aqueous solutions.

\section{Main text}

\subsection{Geopolymers}

Prof. Davidovits, in 1972, submitted application for patenting the use of geopolymer as construction material. $\mathrm{He}$, then, proposed a term Polysialate (Polysilicon-oxoaluminate) to define a series of aluminosilicate binders activated with alkaline solutions at IUPAC conference, and finally, a denotation geopolymer was coined to Polysialate [70-72]. Geopolymers have been prepared using precursors like feldspar; red mud, clays (laterite, illite, and smectite), natural zeolites, kaolinite, metakaolin, and mineral rock powder, wastes from mining, industrial, and agricultural industries for example, bottom ash, rice husk ash, volcanic ash, silica fume, fly ash, granulated blast furnace slag (GBFS), palm oil fuel ash, sludge, iron ore tailings, and waste glass [73-75]. Geopolymers are inorganic polymers, which can be synthesized using reactive precursors rich in aluminosilicates, e.g. fly ash and alkaline activators i.e. $\mathrm{Na}_{2} \mathrm{SiO}_{3}, \mathrm{~K}_{2} \mathrm{SiO}_{3}, \mathrm{NaOH}$ and $\mathrm{KOH}$.

As per reported work, ultrasonification in ultrasonic bath can better dissolve the aluminosilicate components present in fly ash in caustic soda medium. The curing of geopolymer is done at room or slightly higher temperatures below $100{ }^{\circ} \mathrm{C}$, ranging from 20 to $100{ }^{\circ} \mathrm{C}$. The resultant product is procured for few days at room temperature to gain strength and stability. This process is called as geopolymerization (Fig. 1) [57]. When a precursor is geopolymerized, dissolution, precipitation, reorganization, gelation, condensation and polycondensation occur simultaneously to form a geopolymers (Fig. 2) [62, 76]. The key mechanism of geopolymerization involves three stages. Initially, in dissolution process, alkali liquifies the aluminosilicate source minerals and produces free tetrahedral monomeric units of aluminates $\left(\mathrm{AlO}_{4}\right)$ and orthosilicates, the basic unit structure of silicates $\left(\mathrm{SiO}_{4}\right)$ in the solution (alkaline digestion and hydrolysis).

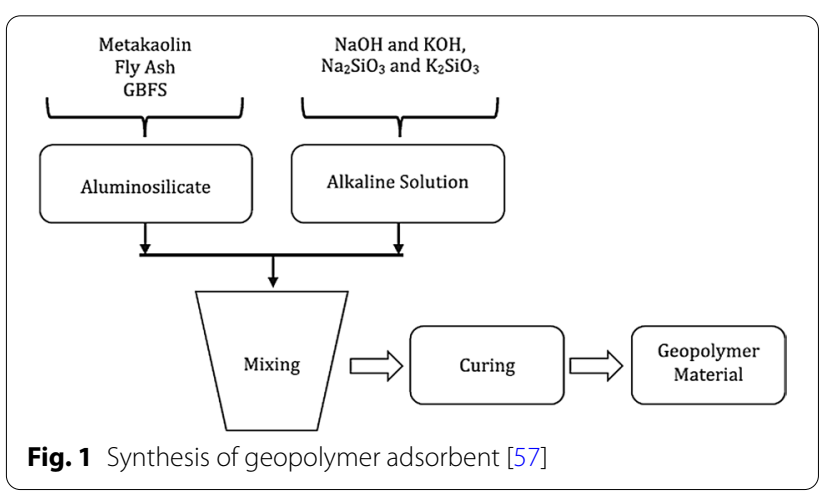




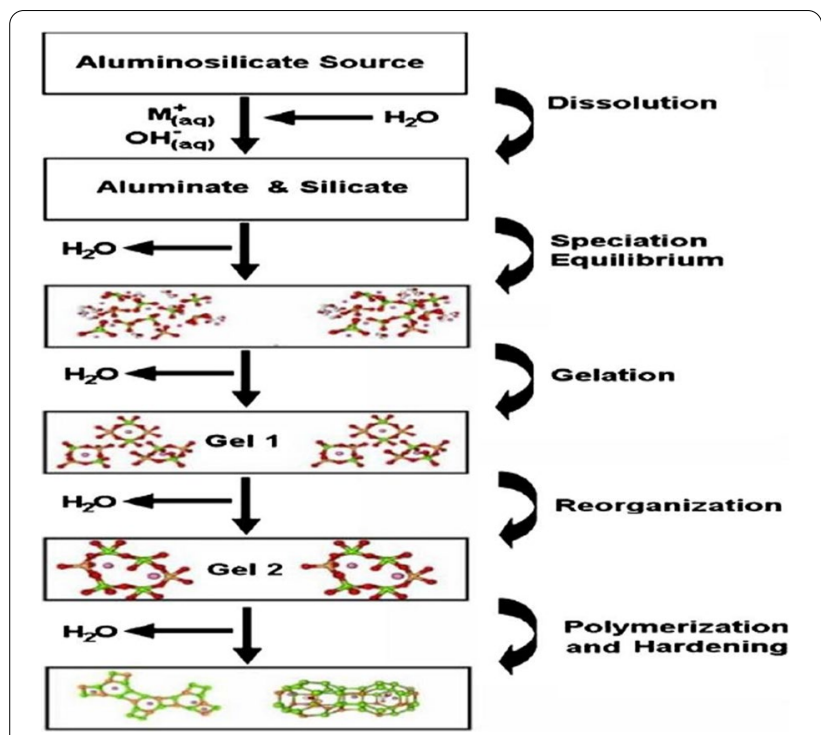

Fig. 2 Conceptual model for geopolymerization [62, 76]

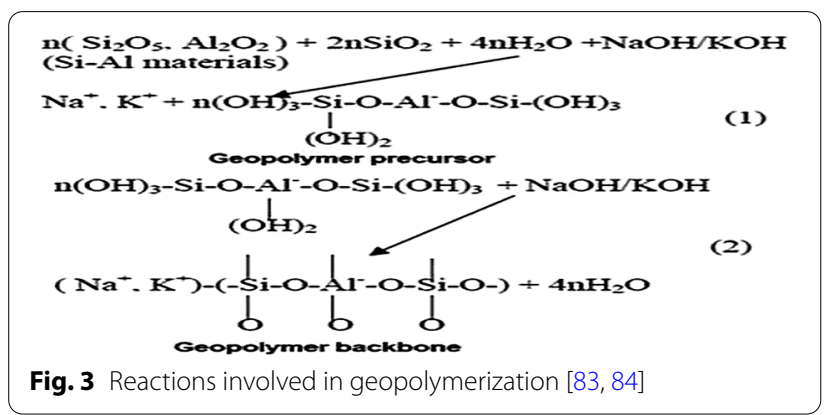

The empirical chemical formula for representing geopolymer is $\mathrm{M}_{a}\left[-\left(\mathrm{SiO}_{2}\right)_{y}-\mathrm{AlO}_{2}\right]_{a} \cdot z \mathrm{H}_{2} \mathrm{O}$, where $\mathrm{a}$ is the degree of polymerization, $y$ is molar mass ratio of $\mathrm{Si} / \mathrm{Al}, \mathrm{M}$ is a cation $\left(\mathrm{Na}^{+}\right.$or $\left.\mathrm{K}^{+}\right)$, and $z$ is no. of attached water molecules [77-82]. In the second step, aluminium and silicon cations are interchanged into oligomers, and then one gel like formation with vast molecular networks is produced through condensation. This emerging gel like formation reorganizes itself, and finally, an aluminosilicate framework, amorphous in nature, is obtained via polycondensation (Fig. 3) [83, 84].

The tetrahedral silicon $\left[\mathrm{Si}(\mathrm{OH})^{4-}\right]$ and aluminium $\left[\mathrm{Al}(\mathrm{OH})^{4-}\right]$ combine for formulating a multifunctional closed cage cavity like ring chain structures which are bonded alternatively via shared oxygen atom, which finds suitable applicability in heavy metal immobilization, nuclear waste management, processing of construction materials, and industrial manufacturing of inorganic membranes. The geopolymers can be classified on the basis of starting material used which is given in Fig. 4 [76].

Nowadays, trends in recycling and converting coal fly ash wastes into useful and valuable products are finding pace [23]. Disposal of huge fly ash mountains has attained a serious concern of scientists as well as administrative authorities [8]. An approach for dealing with the problems associated with the fly ash management issue is the conversion of fly ash into geopolymer, which may be effectively employed in heavy metal remediation. Fly ash is familiar, complex, and abundant anthropogenic material which can be efficiently geopolymerized and used as adsorbents for removing impurities from different environments. The solid fly ash waste is potentially generated from burning of coals in thermal power plants.

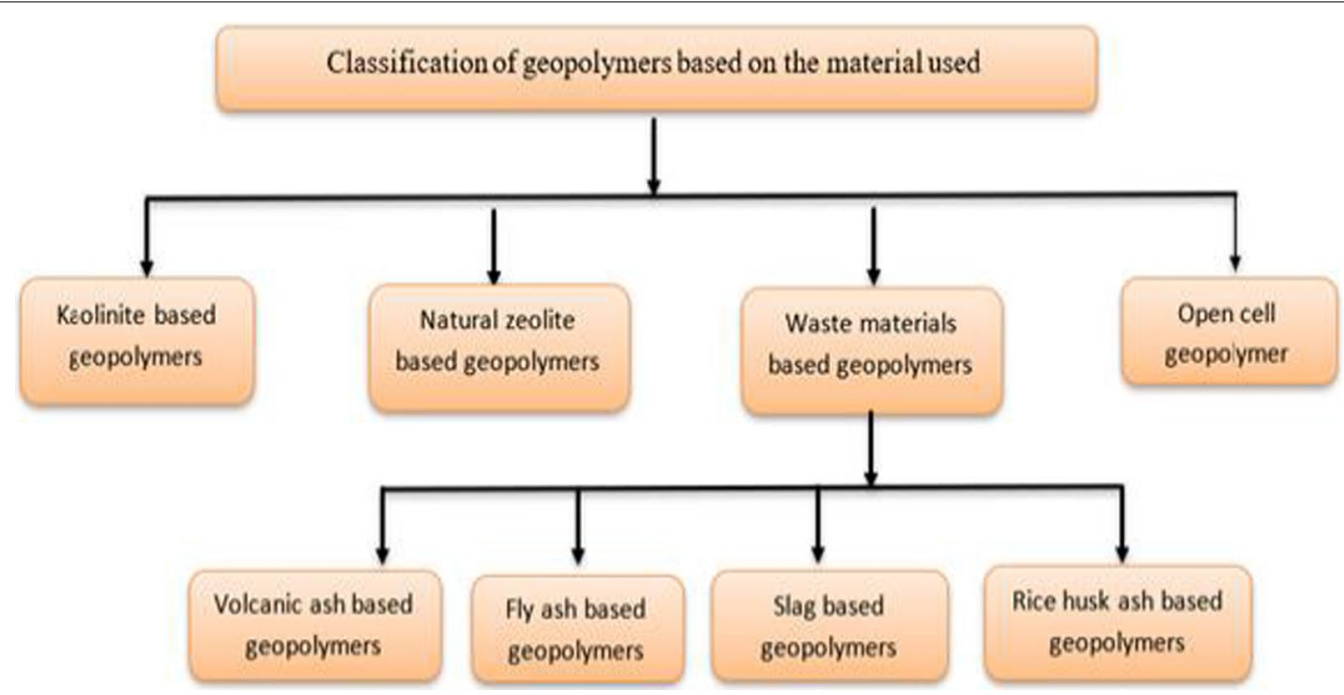

Fig. 4 Classification of geopolymers [76] 
It has been reported in several studies that geopolymer synthesized using fly ash as starting material followed by alkaline activation and curing at room temperatures can be employed in effective remediation of heavy metals in aqueous solutions via adsorption because it contains sufficient amounts of silica and alumina which play an eminent role as precursors for geopolymers. However, fly ash has shown its relevance in context of water treatment but if it is alkaline-treated or activated, it can show better adsorption capacities. The alkaline-activated fly ash is called as geopolymer. These amorphous geopolymers are quite similar to zeolites in terms of composition and structure. Zeolites are the best feasible option used in industrial wastewater treatment. These zeolites can be replaced by fly ash-based geopolymers in future which may render commercial compatibility due to the growing reliance on inexpensive and profusely obtainable fly ash waste as principal feedstock.

\subsection{Fly ash-based geopolymers}

The second most natural fossil fuel source, i.e. coal is abundantly used for producing energy. Approximately 1000 billion tonnes availability of coal in approved reserves make it consumable for electricity production to fulfil the demands and supplies globally. More demand for energy, more extraction of coal from coal mines, and finally more generation of coal ash. Upon combustion of coal in many power plants, $80 \%$ of coal-fired fly ash and $20 \%$ of coal-fired bottom ash are produced which is disposed of in either open area or landfills which causes adverse effects on each and every element of the ecosystem. Fly ash is chemically composed of oxides in different amounts, such as $\mathrm{Al}_{2} \mathrm{O}_{3}, \mathrm{SiO}_{2}, \mathrm{Fe}_{2} \mathrm{O}_{3}, \mathrm{MgO}, \mathrm{CaO}, \mathrm{Na}_{2} \mathrm{O}$, $\mathrm{K}_{2} \mathrm{O}$, and $\mathrm{TiO}_{2}$ with some proportions of trace metals (e.g. Cd, Cr, Se, As) which make it potentially toxic. The compositions of fly ash collected from some different sites are depicted in Table 1.

It is a pozzolanic material with alkaline nature and negatively charged surface which makes it suitable for the adsorption of trace metals from aquatic environments. Furthermore, due to being a cheap and rich source of aluminosilicate, fly ash has drawn the attention of the chemists for reforming this industrial waste into useful adsorbents. Figure 5 [84] displays a few prevalent applications and characteristics of fly ash material. The production rate of fly ash increases when the energy demands increase. Moreover, there is no comprehensive strategy to recycle fly ash into value-added products. Now investigators are exploring the new dimensions in water treatment by converting fly ash into zeolites, catalysts, photocatalysts, and geopolymers and analysing the feasibility as a substitute for costly commercial products.

This development will not only help consumers with efficient low-cost product availability but also waste generators by increasing their incomes and resolving the fly ash management issues with maintaining the aesthetic values of nature [84].

The schematic diagram of different stages of geopolymerization by using fly ash is shown in Fig. 6 [91]. Geopolymers are eco-friendly, inexpensive, ubiquitous, green materials with microporous 3-D structure and better applicable for adsorption processes. The physico-chemical characteristics of the geopolymers depend upon starting materials as precursors, mixture ratio, and curing conditions. Geopolymers due to diverse

Table 1 Composition of chemicals (\%) for raw fly ash by X-ray fluorescence (XRF) spectrometer collected from different sites

\begin{tabular}{|c|c|c|c|c|c|c|c|c|}
\hline Compounds & Compositior & of chemicals & raw fly ash (\%) & & & & & \\
\hline $\mathrm{Al}_{2} \mathrm{O}_{3}$ & 51.72 & 35.84 & 28.87 & 28.73 & 30.51 & 18.50 & $19.1-28.6$ & $12.5-35.6$ \\
\hline Cao & 5.21 & 2.99 & 1.73 & 11.54 & 0.83 & 19.80 & $1.4-22.4$ & $0.5-28.9$ \\
\hline $\mathrm{Fe}_{2} \mathrm{O}_{3}$ & 2.25 & 4.24 & 11.93 & 18.07 & 5.71 & 16.80 & $6.8-25.5$ & $2.6-21.2$ \\
\hline $\mathrm{K}_{2} \mathrm{O}$ & 0.35 & & 0.74 & 0.34 & 1.26 & 2.90 & $0.9-2.6$ & $0.4-4$ \\
\hline $\mathrm{MgO}$ & 0.15 & & 1.39 & 1.79 & 0.59 & 1.89 & $0.7-4.8$ & $0.6-3.8$ \\
\hline $\mathrm{MnO}$ & 0.03 & & & & & & & \\
\hline $\mathrm{Na}_{2} \mathrm{O}$ & 0.05 & & 0.30 & 0.29 & 0.19 & 1.14 & $0.3-1.8$ & $0.1-1.9$ \\
\hline $\mathrm{P}_{2} \mathrm{O}$ & & & & & 0.42 & & $0.1-0.3$ & $0.1-1.7$ \\
\hline $\mathrm{SiO}_{2}$ & 29.47 & 55.54 & 50.73 & 37.88 & 57 & 29.80 & $37.8-58.5$ & $28.5-59.7$ \\
\hline $\mathrm{SO}_{3}$ & & & 0.35 & 0.38 & 0.14 & 4.85 & $0.1-2.1$ & $0.1-12.7$ \\
\hline $\mathrm{TiO}_{2}$ & 1.83 & 1.23 & 1.41 & & 1.61 & & $1.1-1.6$ & $0.5-2.6$ \\
\hline Source & $\begin{array}{l}\text { Coal-fired } \\
\text { power plant }\end{array}$ & $\begin{array}{l}\text { Coal-fired } \\
\text { power plant, } \\
\text { China }\end{array}$ & $\begin{array}{l}\text { Rajhi cement } \\
\text { plant, Jordan }\end{array}$ & $\begin{array}{l}\text { Alborzsarghi coal } \\
\text { company, Iran }\end{array}$ & $\begin{array}{l}\text { Coal-fired } \\
\text { thermal power } \\
\text { plants }\end{array}$ & $\begin{array}{l}\text { Power } \\
\text { plant, } \\
\text { Thailand }\end{array}$ & $\begin{array}{l}\text { Coal-fired } \\
\text { power plant, } \\
\text { U.S }\end{array}$ & $\begin{array}{l}\text { Coal-fired } \\
\text { power plant, } \\
\text { Europe }\end{array}$ \\
\hline References & {$[85]$} & {$[86]$} & [87] & {$[88]$} & [89] & {$[90]$} & {$[60]$} & {$[60]$} \\
\hline
\end{tabular}




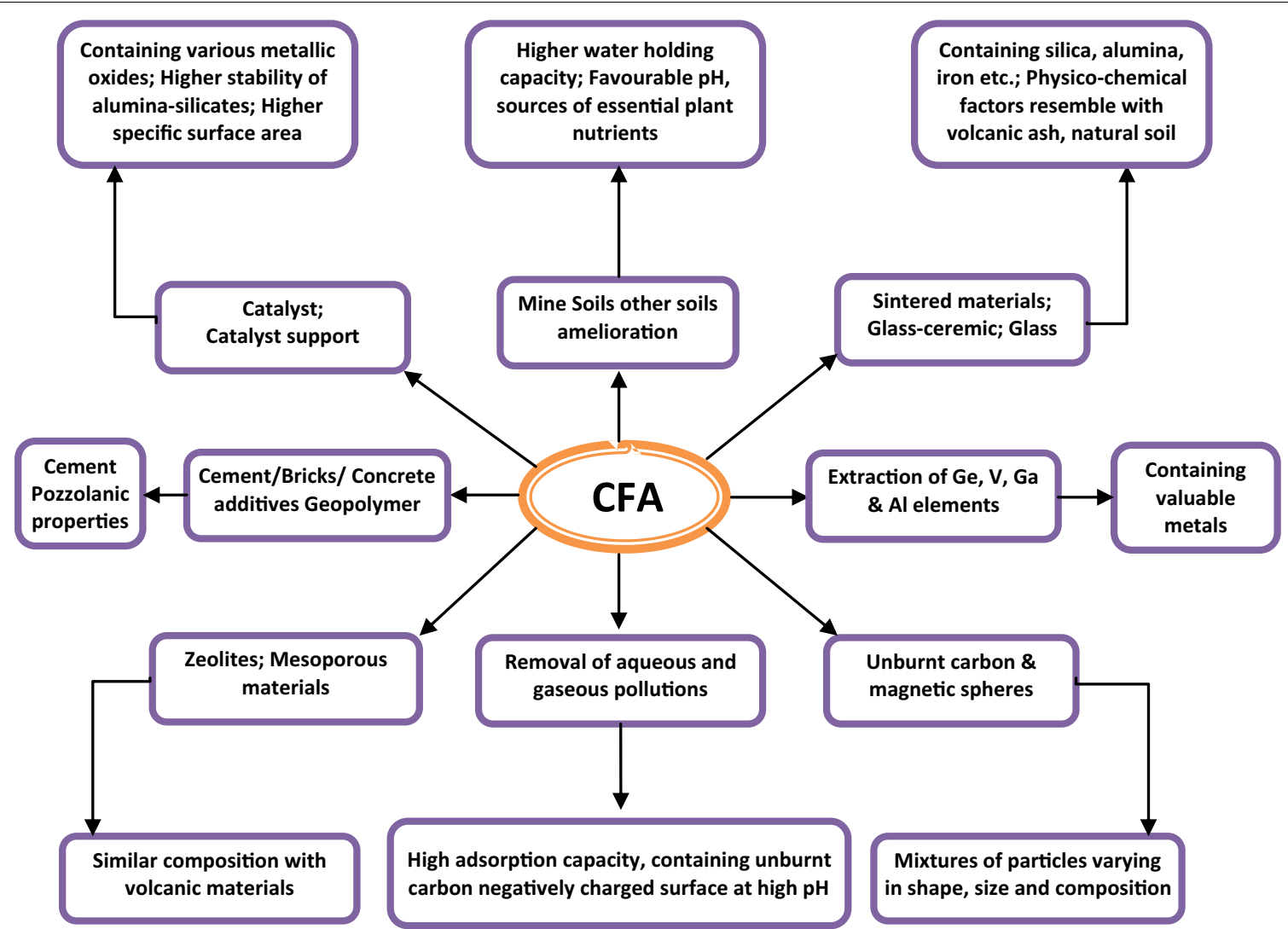

Fig. 5 Prevalent applications and properties of coal derived fly ash [84]

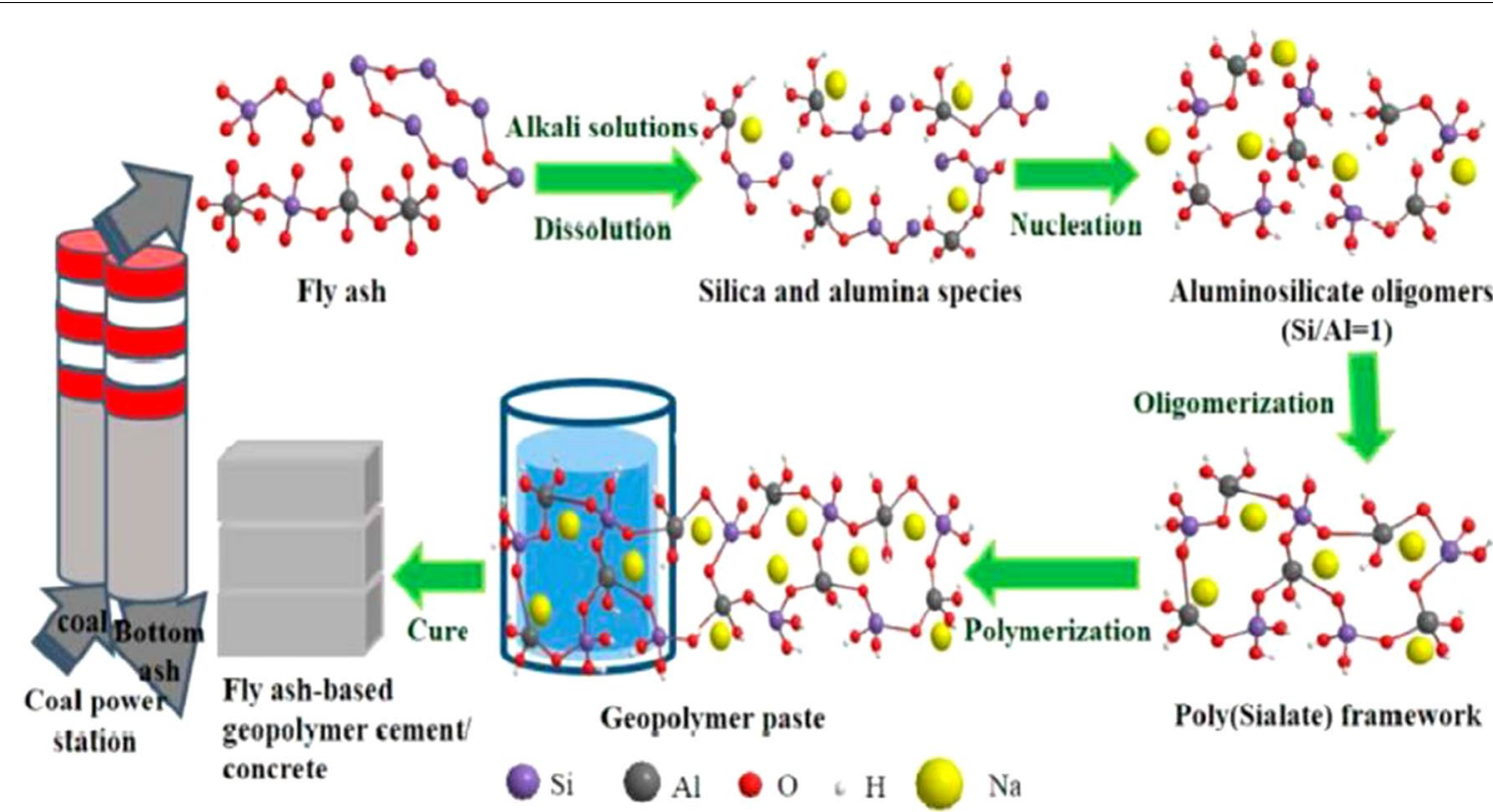

Fig. 6 Schematic diagram of different stages of geopolymerization of fly ash [91] 


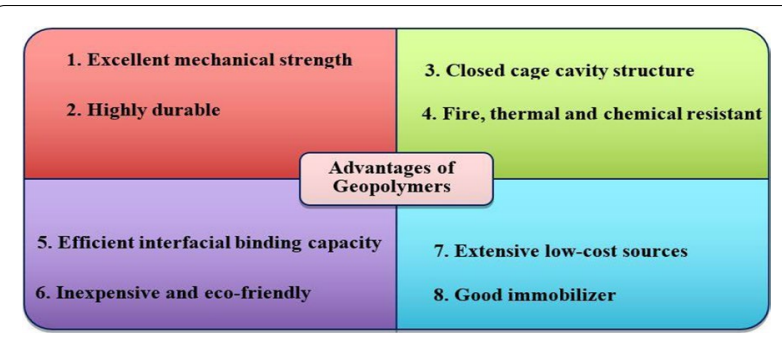

Fig. 7 Advantages of geopolymers [94]

advantages (Fig. 7) [94] have been used as adhesives, construction material, drug delivery agents, fire and chemical resistance applications, catalysts, precursors of advanced ceramics, coatings, hydrogen storage, oxygen carriers and other diverse applications [92, 93].

Recently, geopolymers have effectively been developed and utilized as adsorbents for adsorption of heavy metals like cadmium, chromium, nickel, boron, lead, fluoride, copper, phosphate, mercury, zinc, barium, cobalt, $\mathrm{NO}_{x}$, some radionuclides, e.g. ${ }^{137} \mathrm{Cs}$ and ${ }^{90} \mathrm{Sr}$ as well as dyes from wastewater. The high surface area, porosity, chemical resistance, tunable nature for modifications, mechanical strength, durability and negative charge on aluminium attribute a significant mechanism for removal of impurities by attracting cations. Although aluminosilicate materials are itself good adsorbents, geopolymerization increases their capabilities and efficiencies for better adsorption of heavy metals from aqueous medium via ion exchange process. The incorporation of nanomaterials to geopolymers, such as graphene, nano-clay, nano- $\mathrm{SiO}_{2}$, and carbon nanotubes, can alter the characteristics of concrete's geopolymer. The equal distribution of nano-sized materials in geopolymers is the most crucial parts for enhancing their catalytic performance. The structure of geopolymer remains stable and intact even under extreme vigorous conditions. This salient feature makes geopolymer compatible to use in a number of scientific fields [76, 95-97].

Some factors which monitor the geopolymerization process [91] are discussed as follows:

- Selection of type of aluminosilicate containing raw materials

- Surface area and glassy content of solid raw materials

- Sufficient amounts of aluminium $(\mathrm{Al})$ and silicon $(\mathrm{Si})$

- Presence of natural calcium, iron, and inert particles in Fly ash

- Physico-chemical modification

- Optimization of curing temperatures and pressures

- Time duration and curing mode

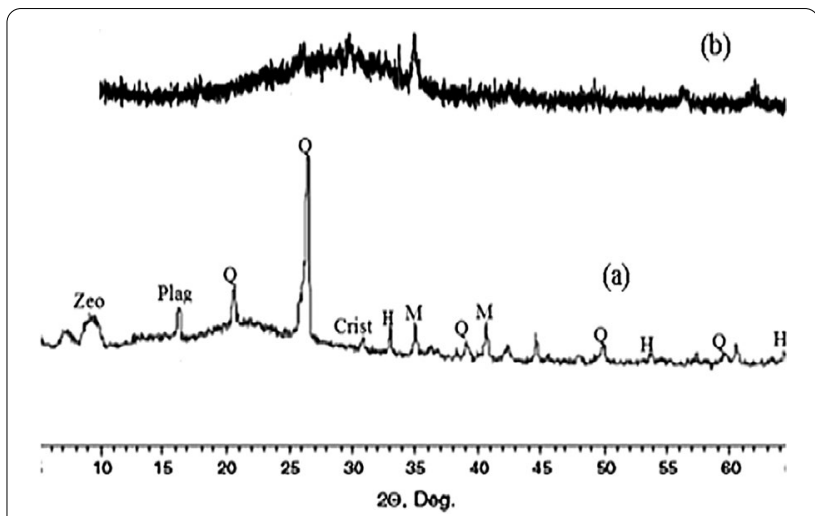

Fig. 8 XRD sequence of untreated fly ash (a) the synthesized geopolymer (b) (H, Hematite; M, Mullite; Q, Quartz; Plag, Plagioclase; Zeo, Zeolite) [87]

- Selection of alkaline concentrations

- Alkali to precursor ratio

- Water content to $\mathrm{Na}_{2} \mathrm{O}$ molar proportion and geopolymeric solids proportions

- $\mathrm{Na}_{2} \mathrm{O}$ to $\mathrm{SiO}_{2}$ and $\mathrm{SiO}_{2}$ to $\mathrm{Al}_{2} \mathrm{O}_{3}$ ratio.

\subsection{Characterization of fly ash-based geopolymers}

Characterization of a developed material is a very significant step to elucidate its properties. It is generally carried out by performing a number of analyses using various instruments. The chemical composition analysis of fly ash was done after geopolymerization using XRF Spectrometer and the amounts of chemical solids were found in following proportions: $\mathrm{SiO}_{2} 39.90 \%, \mathrm{Al}_{2} \mathrm{O}_{3} 19.70 \%, \mathrm{Fe}_{2} \mathrm{O}_{3}$ 7.50\%, $\mathrm{CaO} 2.43 \%, \mathrm{MgO} 1.13 \%, \mathrm{~K}_{2} \mathrm{O} 1.08 \%, \mathrm{Na}_{2} \mathrm{O} 11.72 \%$, $\mathrm{TiO}_{2} 0.50 \%, \mathrm{SO}_{3} 0.25 \%$, and loss on ignition (LOI) $14.69 \%$ [85]. It was found that the amounts of sodium content and loss on ignition (LOI) was substantially more than it observed in the raw sample of fly ash, which indicates that $\mathrm{Na}^{+}$and $\mathrm{OH}^{-}$group are now the structural constituents of synthetic geopolymer [98].

$\mathrm{X}$-ray diffraction (XRD) sequence of both raw fly ash and fly ash-based geopolymer as shown in Fig. 8 [87] suggests that both the ash sample has amorphous structure which imparts reactivity to fly ash and approximately all the crystal lattice phases present in raw fly ash were disappeared during geopolymerization.

It was identified that geopolymer also contains nanocrystalline zeolites but XRD is unable to detect these small sized zeolite crystals. Mineral phase analysis of geopolymer was performed which showed the loss of all recognized minerals in the raw sample [87].

Some chemicals for example, soyabean oil, cetyltrimethylammonium bromide $(\mathrm{CTAB}), \mathrm{Fe}_{2} \mathrm{O}_{3}$, surface 
foaming agents (SDS), and stabilizers $\left(\mathrm{H}_{2} \mathrm{O}_{2}\right)$ have been used for modification of the geopolymers to improve the adsorption rates of heavy metal cations by increasing surface area, pore size and volume of geopolymeric adsorbents. The pore size, pore volume and geopolymer adsorbents have a surface area that varies between $16.2-216 \mathrm{~m}^{2} \mathrm{~g}^{-1}, 2-50 \mathrm{~nm}$ (mesoporous materials), and $0.05-0.36 \mathrm{~cm}^{3} \mathrm{~g}^{-1}$, respectively. Geopolymer microstructure and geopolymer with porous structure were analysed using Optical microscope which confirmed that the addition of $\mathrm{H}_{2} \mathrm{O}_{2}$ increased the surface porosity $27.9 \%$ to $74.6 \%$ in porous geopolymer [ $[81,85$, 99]. This increase in porosity was also supported by the results obtained from mercury intrusion porosimetry and SEM as shown in Fig. 9a-c [85]. Figure 10i-ix [84] demonstrates the change in microstructures using detailed microscopic studies using SEM images of geopolymers activated with different alkalis with varying concentrations and curing temperatures $[91,100]$.

BET surface area analysis concluded that the fly ash that has been sieved using 200 mesh sieve having $12.141 \mathrm{~m}^{2} / \mathrm{g}$ surface area and the surface area of the fly ash-modified geopolymer that passed through a 50 mesh standard sieve was $27.205 \mathrm{~m}^{2} \mathrm{~g}^{-1}$ [98].

Fourier transform infrared spectroscopy (FTIR) elucidates bonding nature between atoms. Difference in spectra of raw fly ash and synthesized fly ash-modified geopolymer can be detected by comparing both of them. FTIR analysis of developed fly ash-based geopolymer showed main band peak $1015.33 \mathrm{~cm}^{-1}$ as configured in Fig. 11a [101]. New bands appeared in all geopolymeric materials at $1653.01 \mathrm{~cm}^{-1}$ and $3456.22 \mathrm{~cm}^{-1}$ which were assigned to deformation vibrations $(\mathrm{H}-\mathrm{O}-\mathrm{H})$ and compressing-stretching vibrations $(-\mathrm{OH}, \mathrm{H}-\mathrm{O}-\mathrm{H})$. The FTIR spectra of geopolymer activated with different concentrations $(6 \mathrm{M}$, $8 \mathrm{M}, 10 \mathrm{M})$ of alkaline sodium hydroxide $(\mathrm{NaOH})$ and cured at $60{ }^{\circ} \mathrm{C}$ as shown in Fig. 11b [84, 100]. FTIR peaks at $460 \mathrm{~cm}^{-1}$ and $550 \mathrm{~cm}^{-1}$ observed, which are attributed to deformation vibrations of $\mathrm{Al}-\mathrm{O} / \mathrm{Si}-\mathrm{O}$. Geopolymer activated with $8 \mathrm{M}$ sodium hydroxide showed a broader band, which can be assigned to indicative presence of structural water in large amounts (Fig. 11b) [84, 100].

\section{Research trends}

This manuscript presents literature review on fly ash-based adsorbents in scientific fields of importance. Valid databases like WoS, Elsevier, Scopus, and Research gate were searched for collecting different sources and information. The paper was structured to focus on problems related to fly ash, possible solutions, geopolymerization of fly ash, characterization and finally performance for depollution. The analysis of evolution trends by mapping the key searches in this research field is given in Fig. 12 [102] and Fig. 13 [103].

\section{Fly ash-modified geopolymers for heavy metal remediation}

Geopolymers structure is supposed to be an alkali-based aluminosilicate hydrate with a 3-D network and consist units of silicate and alumina in tetrahedral form attached altogether through covalent bonding, negatively charged cations that are connected with the tetrahedral $\mathrm{Al}^{3+}$ charge and are balanced by alkaline cations. When heavy metals are immobilized in geopolymers, the adhesion process for heavy metals is essentially the substitution of alkaline cations, with the heavy metal cations bonding to and immobilizing in the aluminate tetrahedral units of the geopolymeric structures. Hydrochloric acid $(\mathrm{HCl})$ treatment of fly ash followed by washings with distilled water cleans the adsorbent and improves its adsorption capacity by removing impurities.

Alkali activation is a typical chemical treatment for fly ash that is used in a variety of applications. The fly ash is mixed with alkaline solutions and allowed to cure at a high temperature to generate amorphous solid materials, which are referred to as fly ash-based geopolymers. They have a porous structure that is both linked and open, as well as a net negative charge, which are both significant advantages for adsorption operations. Fly ashbased geopolymers are considered to be environmentally acceptable, effective, and low-cost adsorbent materials because of their low cost and high effectiveness. As a result, they have been successfully used for the adsorption of heavy metal cations, such as $\mathrm{Cu}^{2+}, \mathrm{Pb}^{2+}, \mathrm{Zn}^{2+}$, and $\mathrm{Cd}^{2+}$, among others. When fly ash is transformed into geopolymers, it is subjected to a series of simultaneous processes, including hydrolysis and condensation. Under alkaline conditions, hydrolysis reactions catalysed by hydroxyl ions would result in the breakage of $\mathrm{Si}-\mathrm{O}-$ $\mathrm{Si}$ and $\mathrm{Si}-\mathrm{O}-\mathrm{Al}$ bonds, resulting in the formation of free $\mathrm{SiO} 4$ and $\mathrm{AlO} 4$, as well as dimeric, trimeric, and oligomeric (alumino)silicates. Concurrently, condensation processes, which are also accelerated by hydroxyl ions, will take place to build the three-dimensional polymeric structure of new $\mathrm{Si}-\mathrm{O}-\mathrm{Si}$ and $\mathrm{Si}-\mathrm{O}-\mathrm{Al}$ links. There are at least four common alkali kinds, namely $\mathrm{NaOH}, \mathrm{KOH}$, $\mathrm{NaOH}+\mathrm{Na}_{2} \mathrm{SiO}_{3}$, and $\mathrm{KOH}+\mathrm{Na}_{2} \mathrm{SiO}_{3}$. The first two are commonly used in the preparation of geopolymers as adsorbents, while the last two are used in the construction industry [87, 90, 104].

Microstructural analysis like scanning electron microscope (SEM) illustrates about the texture of surface particles and morphology of the compound (Fig. 14) [104]. 


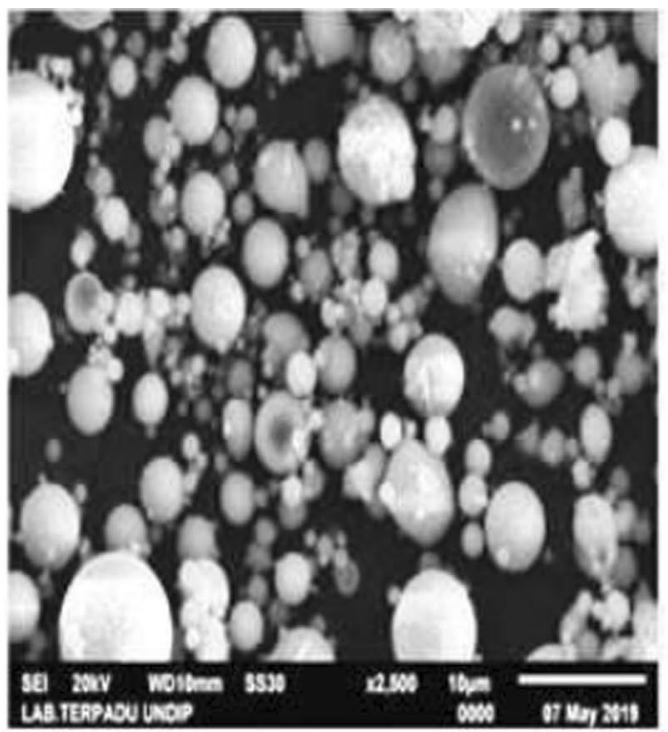

(a)
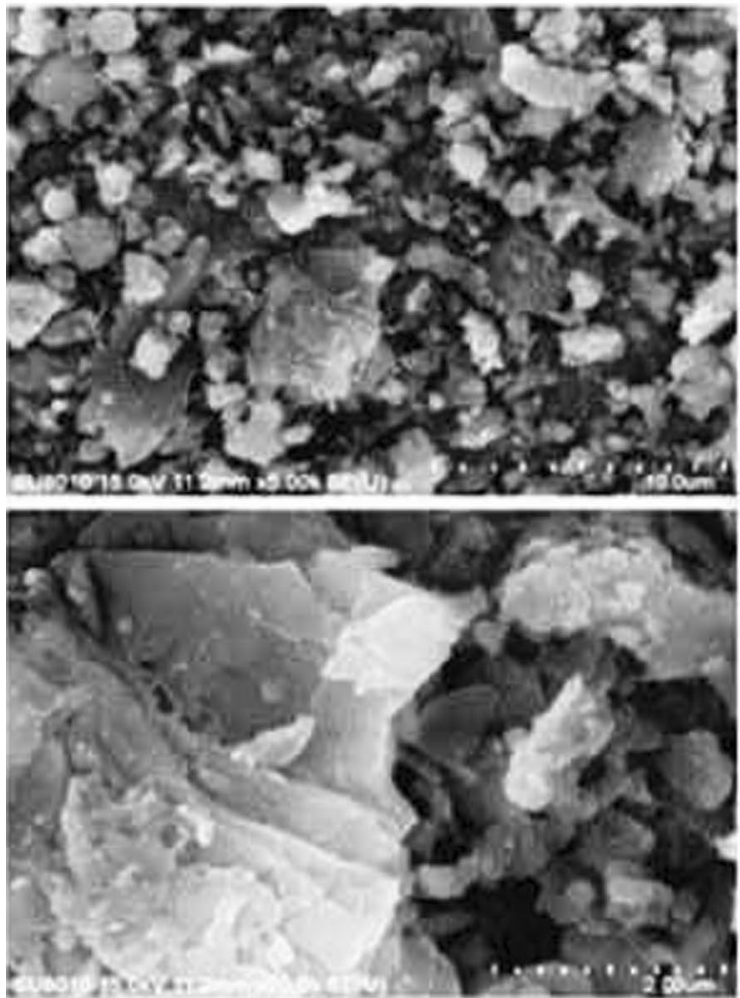

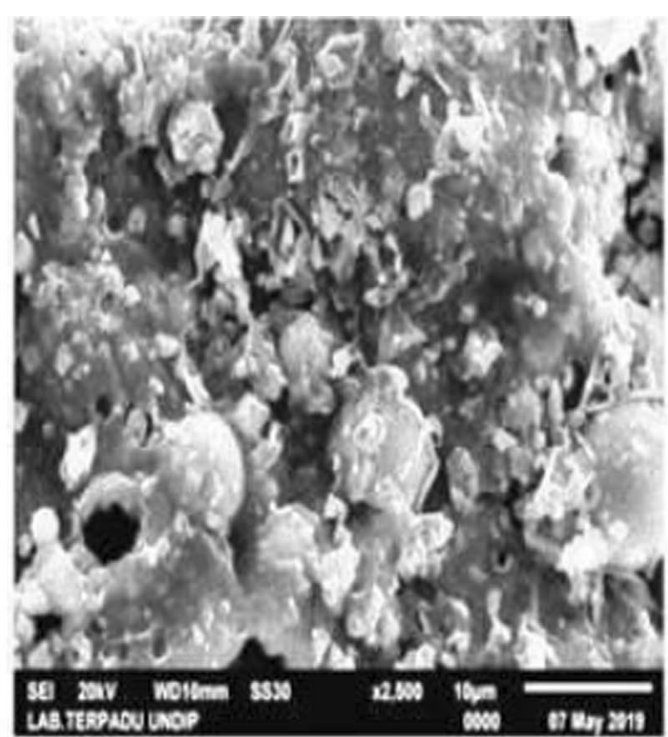

(b)
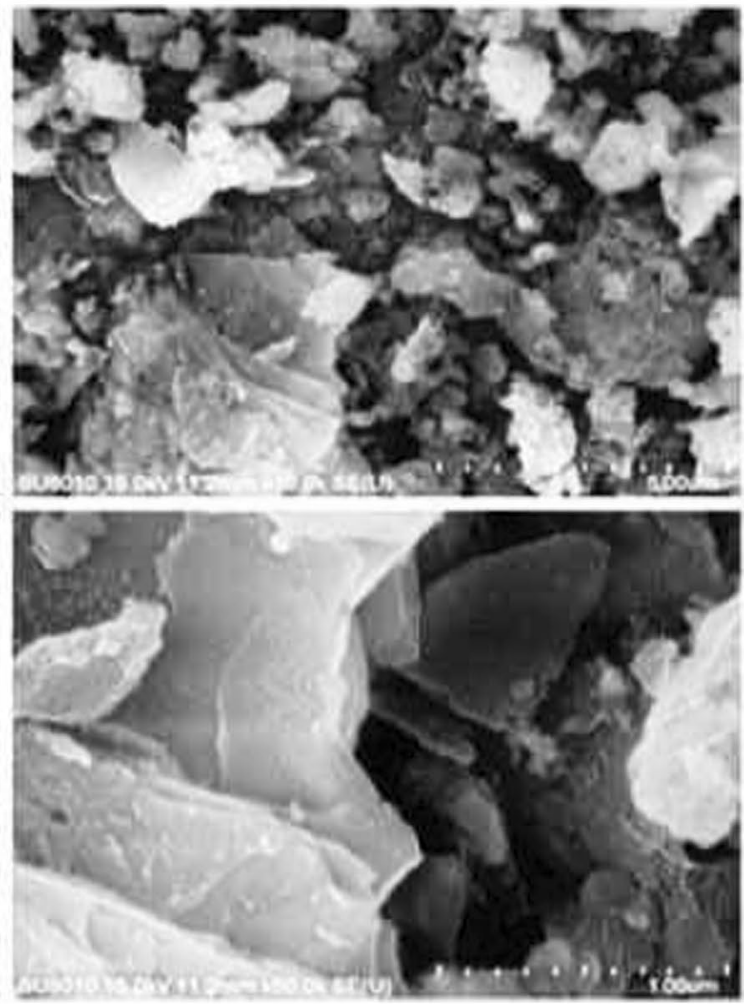

(c)

Fig. 9 SEM micrographs of $\mathbf{a}$ fly ash and $\mathbf{b}$ fly ash-based geopolymer [85]. c SEM micrographs of fly ash at different magnification values [85]

The surface properties are a deciding factor which affects the adsorption rate and capacity.

Geopolymers have been used in the form of powder, granules, monoliths and spheres. Geopolymers followed by treatment with water, sodium chloride, hydrochloric acid, sulphuric acid, acetic acid, nitric acid, sodium hydroxide and potassium hydroxide have been used in immobilization of manganese, zinc, nickel, cadmium, 

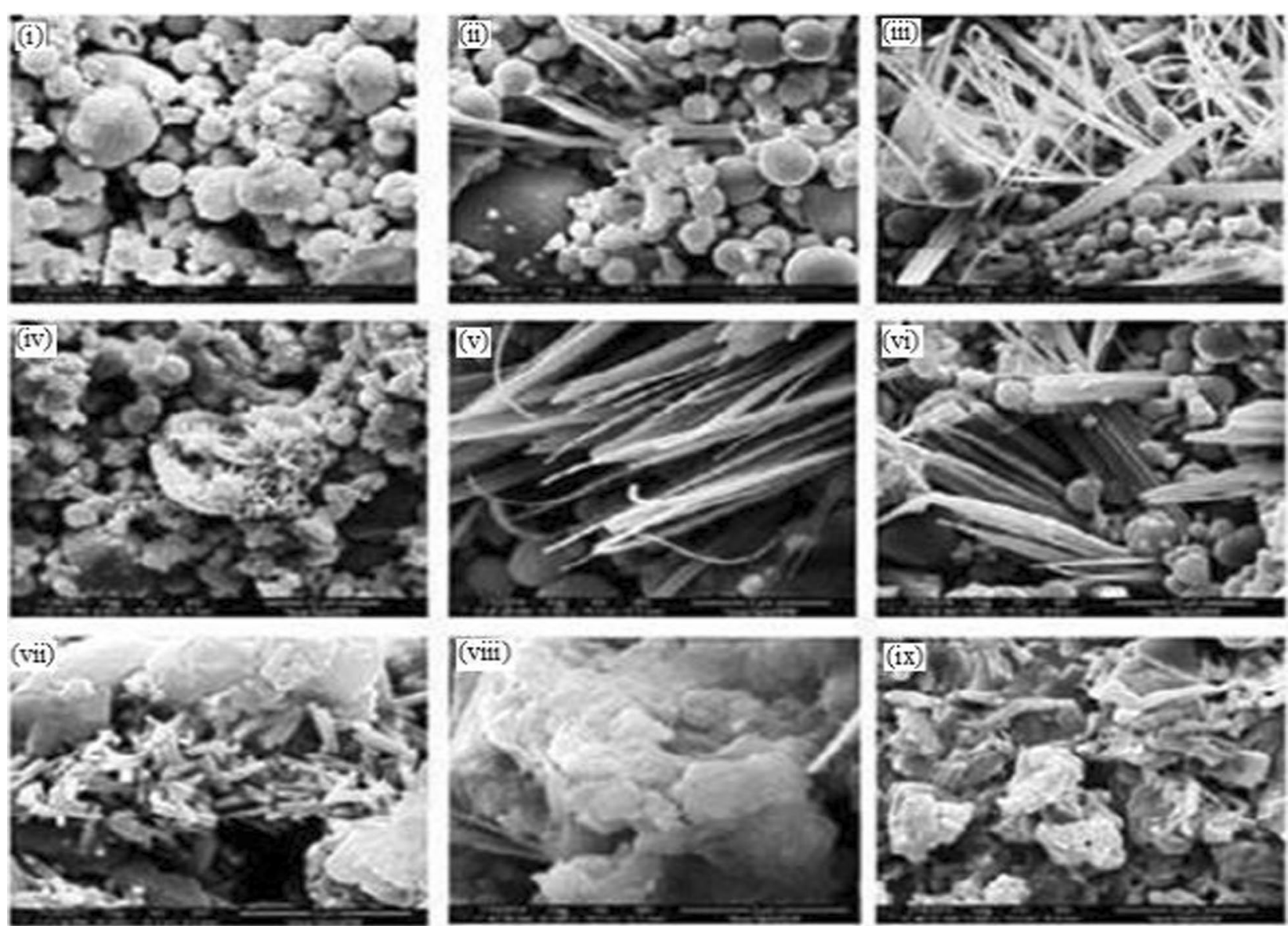

Fig. 10 FA-modified geopolymers SEM images i 6M27; ii 6M45; iii 6M60; iv M27; v 8M45; vi 8M60; vii 10M27; viii 10M45; ix 10M60 [84]

tin, copper, chromium, lead, barium, calcium, arsenic, caesium, cobalt, magnesium, ammonium, and sulphate from aqueous solutions. Figure 15 [104] illustrates a diagrammatic depiction of the substitution process between heavy metals and alkali cations. The removal efficiencies of the alkali-activated fly ash-based geopolymer adsorbent were much higher than those of fly ash. Geopolymers based on fly ash have a larger porous surface area than fly ash itself, making them more porous.

A significant amount of potential exists for the attraction and capture of cations or heavy metal ions on the surface of aluminium due to the negative charges present on it.

The highest adsorption of copper was observed using amorphous geopolymer due to dissolved glass phases of fly ash and it showed better adsorption capacities than raw fly ash. Parameters like adsorbent/adsorbate proportion, dose of adsorbent, temperature, contact duration and initial conc. of adsorbate $\left(C_{o}\right)$ were optimized, and the highest sorption efficiency was found to be $152 \mathrm{mg} / \mathrm{g}$ at $45^{\circ} \mathrm{C}$ with adsorbent dosage of $2 \mathrm{~g} / \mathrm{L}$ for $2 \mathrm{~h}$
[87]. Onutai et al. discussed about fabrication of geopolymer-polymer composite fibre. Using the phase inversion technique, these fibres were created by combining powdered geopolymer with a solution of Polyethersulfone (PES)-N-Methyl-2-pyrrolidone (NMP), and extruding the resulting slurry, which resulted in the transformation into a pervious fibre (BET surface area, $168.30 \mathrm{~m}^{2} / \mathrm{g}$ ). The geopolymer composite fibre followed the order of $\mathrm{Ni}^{2+}<\mathrm{Cd}^{2+}<\mathrm{Cu}^{2+}<\mathrm{Pb}^{2+}[90]$.

Another alkali-activated fly ash-based geopolymer was formulated using $10 \mathrm{~N} \mathrm{NaOH}$ and sodium silicate solution. It was applied for treating $\mathrm{Cu}^{2+}, \mathrm{Fe}^{2+}, \mathrm{Mn}^{2+}, \mathrm{Zn}^{2+}$ in aqueous solutions and concentrations were quantified using AAS [98].

Fly ash was activated with sodium hydroxide solution to prepare fly ash-based geopolymer and examined for copper removal from aqueous solutions. The results obtained confirm the suitability of fly ash-based geopolymer for heavy metal removal [101].

Fly ash-modified geopolymers are prepared and utilized as adsorbent for heavy metal remediation in 


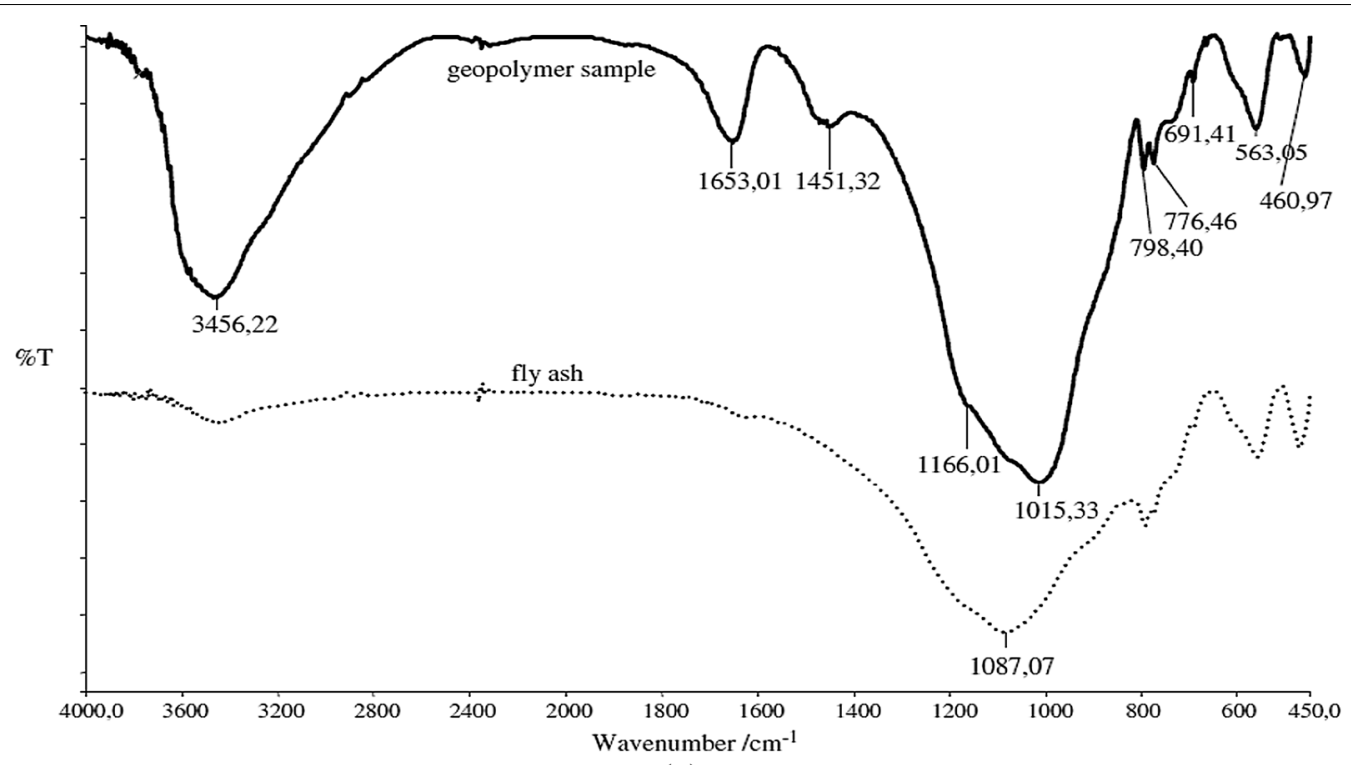

(a)

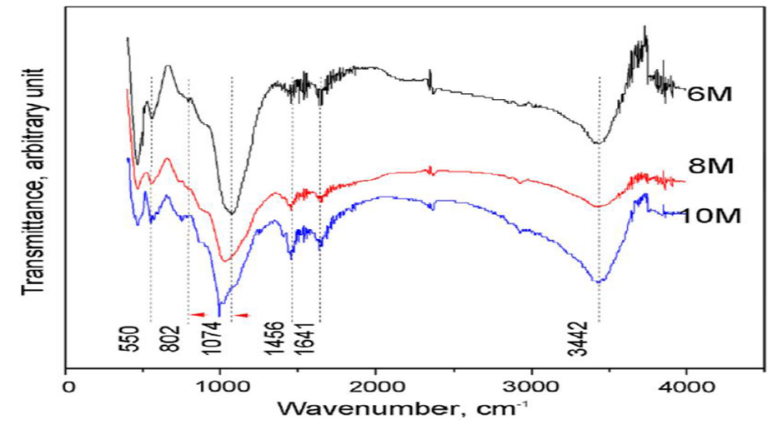

(b)

Fig. 11 a FTIR pattern of the raw FA and modified FA geopolymer [101]. b FTIR spectra for geopolymer sample [84, 100]

aqueous environment. Fly ash is activated with alkali using a number of $\mathrm{Na}^{+}$or $\mathrm{K}^{+}$enriched compounds. The influence of alkali enrichment on structural modification and its effect on the adsorption capacity of geopolymer as an adsorbent were investigated in this study. According to Darmayanti et al. [104], geopolymers with sodium ions are observed to be more organized in comparison to that activated with potassium ions based alkali systems. Furthermore, the addition of silicates also improves the structure. This study focuses on design and fabrication of geopolymer adsorbent for heavy metal remediation [104].

A synthesized fly ash-based geopolymer obtained adsorptive efficiency of $118.6 \mathrm{mg} / \mathrm{g}$ through equilibrium time achieved in $1 \mathrm{~h} 30 \mathrm{~min}$ for lead [105].

The literature reviewed by Rasaki et al. gave an insight about geopolymers which offers feasible solutions to world's environmental problems and challenges related to wastewater treatment, energy production and slag management. Its porosity and chemical composition similar to zeolites is an ultimate solution for wastewater treatment [106]. Wang et al. [107], Al Zboon et al. [108], and Javadain et al. [109] performed studies on removal of copper, lead and cadmium ions, respectively using fly ash-based geopolymers. Table 2 shows heavy metal removal using fly ash-based geopolymer adsorbents.

\section{Other adsorbents based heavy metal adsorption}

There are a variety of adsorbents available for heavy metal clean-up that are not based on fly ash. Modification in fly ash-modified geopolymers also resulted in good sorption of heavy metals. The metakaolin and alkali solution were mixed and condensed at room temperature, and then, the adsorption efficiency was examined by using obtained geopolymer for different heavy metal cations (i.e. lead, chromium, copper, and cadmium) in aqueous medium under varying experimental conditions. The optimum 


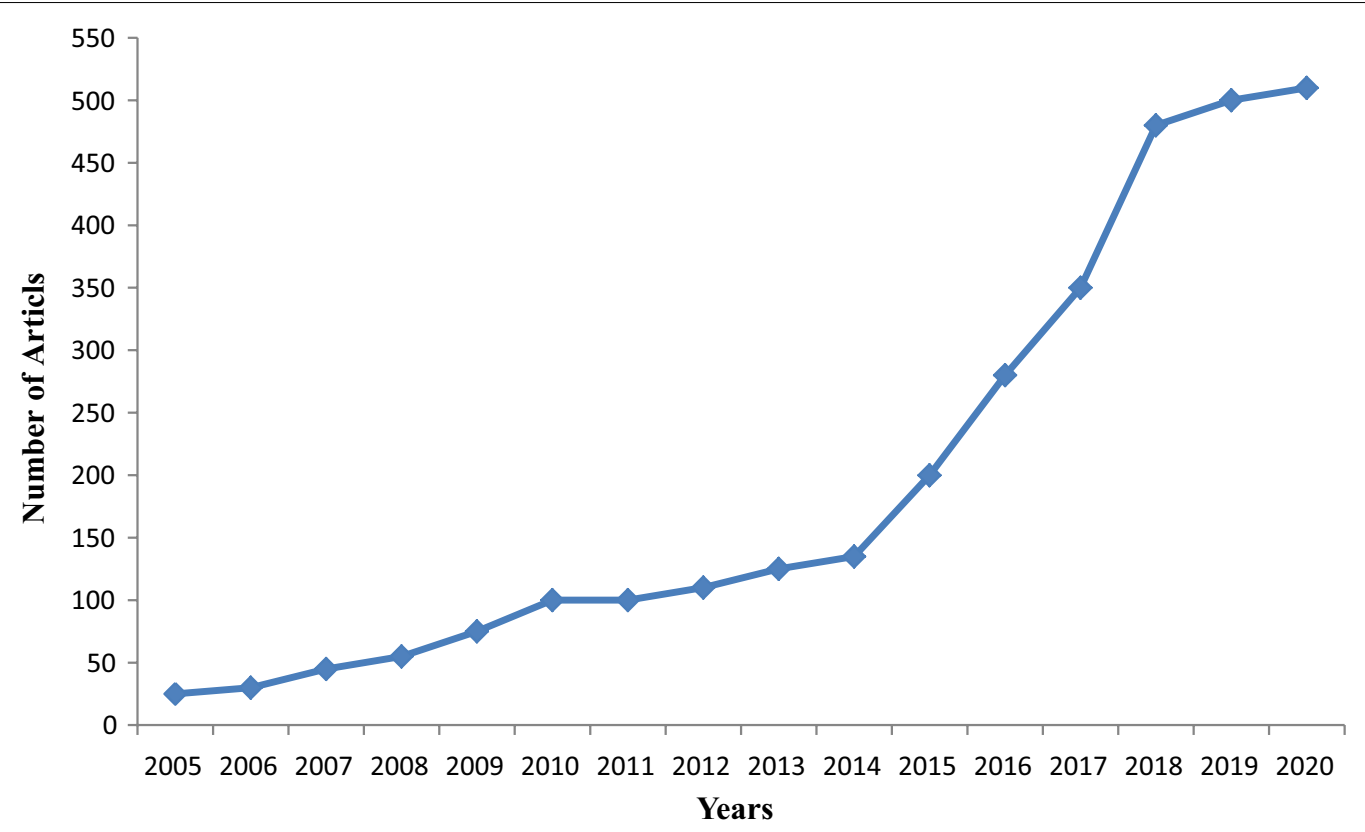

Fig. 12 Distribution of annually total number of papers [102]

adsorption was found to be for lead. The data fitted with both pseudo-second-order and Langmuir equations [68].

Composites of Alginate-chitosan geopolymer produced using metakaolin for the modification of geopolymer and mix of sodium alginate liquid with chitosan for lead treatment in wastewater. The results showed high adsorption capacity (120.45-142.67 $\mathrm{mg} \mathrm{g}^{-1}$ ) for lead at $\mathrm{pH} 5$ and $25^{\circ} \mathrm{C}$ [110].

Red mud (RM), a sort of alkaline solid waste generated from industries, can be a great source as a starting material for geopolymers with GBFS that can have the capabilities for purification of water systems and helps in heavy metal remediation [111].

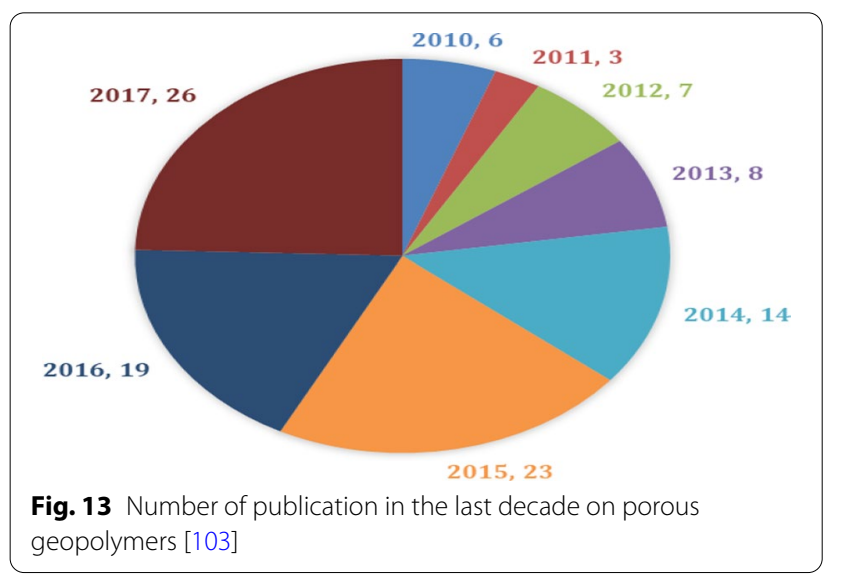

Due to their large surface area, high pore volume, enhanced adsorption capacity in comparison to the zeolites, support and strength from the geopolymer matrix, geopolymer-zeolite hybrid composites have the potential to be used as adsorbents and membranes in separation, purification, and pervaporation methods. The usage of industrial leftovers for the development of new ideas may also be beneficial economically (waste to wealth) [112].

The development of a low-cost metakaolin-based geopolymer for the removal of manganese, $\mathrm{Mn}(\mathrm{II})$, and cobalt, $\mathrm{Co}$ (II), from aqueous medium was accomplished. At $30{ }^{\circ} \mathrm{C}$, the experiments were carried out in batch to determine the effects of various factors such as $\mathrm{pH}$, adsorbent dose, duration of contact, and metallic ion concentration at starting on the metal removal performance. $\mathrm{Mn}$ (II) and $\mathrm{Co}(\mathrm{II})$ adsorption were shown to follow a pseudo-second-order kinetic model, based on the results of the kinetic investigations. Also discovered was that no $\mathrm{pH}$ modification was required to enhance adsorbent efficiency, and the adsorption capacity was observed to be slightly responsive to temp. and ion strength [113].

Mine waste- and pyrophyllite-modified geopolymer showed $98-99 \%$ adsorption for cobalt, cadmium, nickel and lead in aqueous medium at initial conc. of 10 $\mathrm{mgL}^{-1}, \mathrm{pH} 7.8$ at $343 \mathrm{~K}$ temperature [114]. A metakaolin-based geopolymer modified using cetyltrimethylammonium bromide surfactant adsorbed $\mathrm{Cu}^{2+}$ ions with removal efficiency of $40 \mathrm{mg} / \mathrm{g}$ [115]. A two-step preparation of geopolymer from kaolin was performed and 

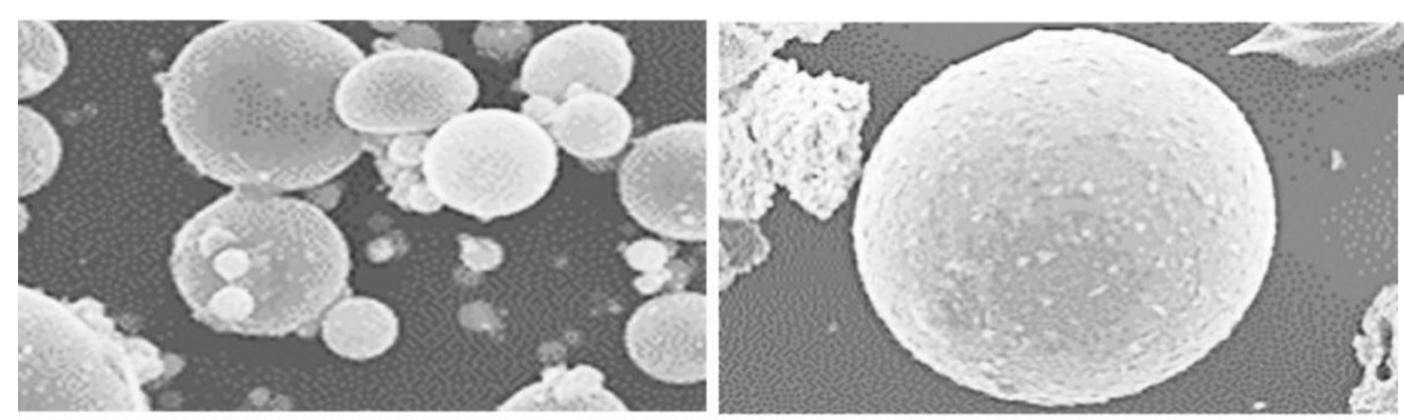

(v)
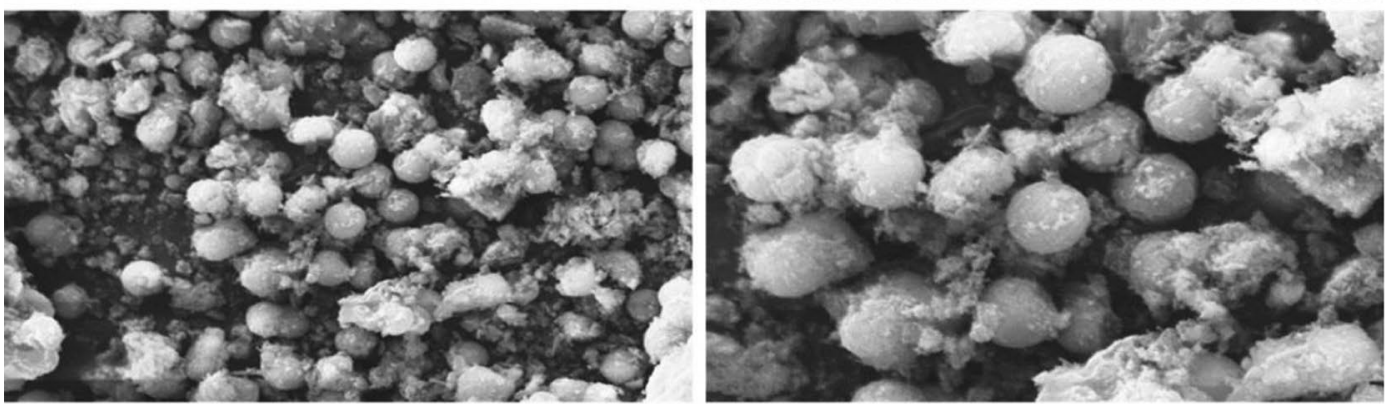

(iv)
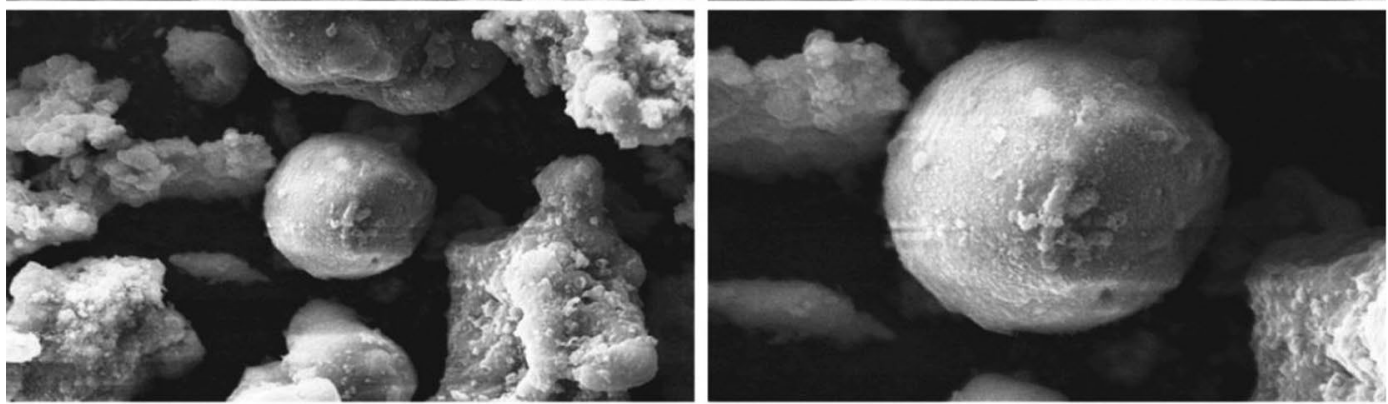

(iii)
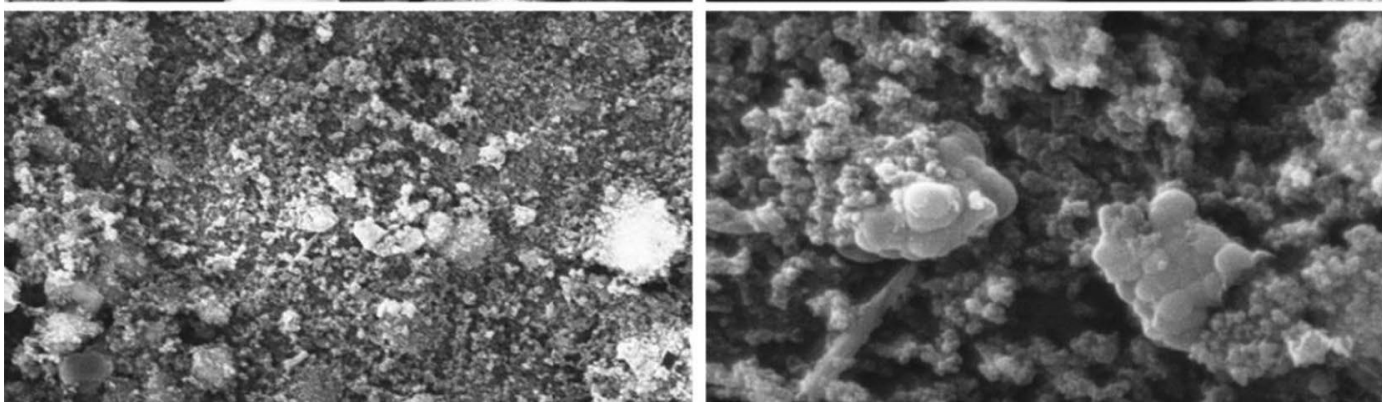

(ii)
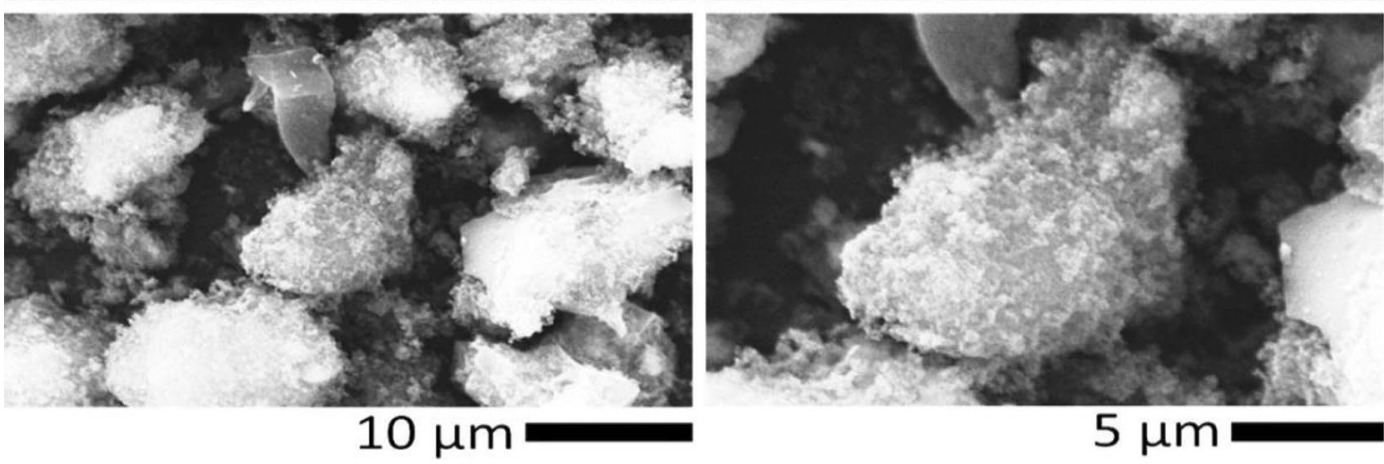

(i)

Fig. 14 SEM views of i FA, ii Na-GP, iii K-GP, iv NaSil-GP, and v KSil-GP [104] 


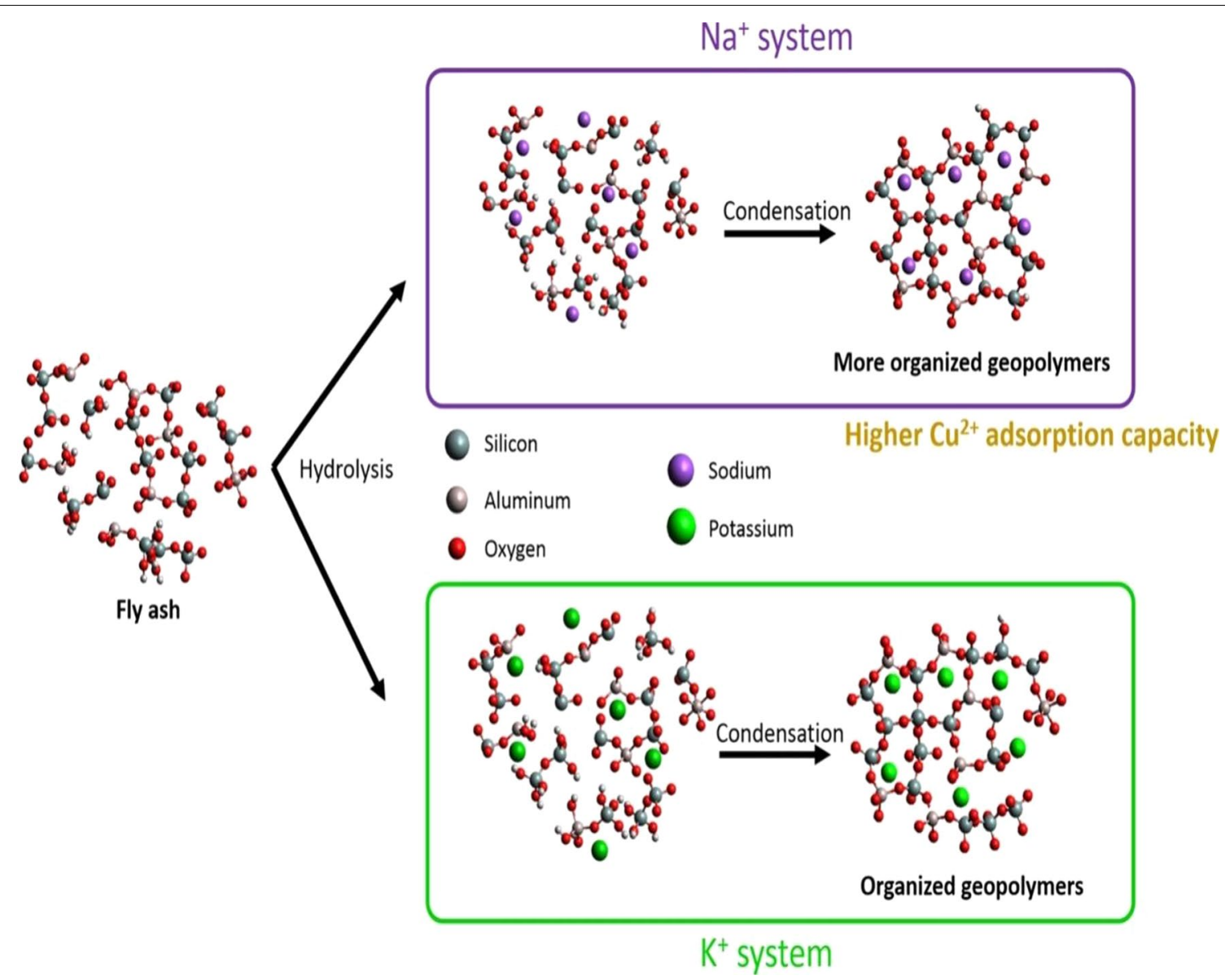

Fig. 15 Heavy metal and alkali cation substitution [104]

Table 2 Removal of heavy metals by fly ash-based geopolymer (FAG) adsorbents by adsorption process from aqueous solutions

\begin{tabular}{|c|c|c|c|c|c|c|c|}
\hline S. No & $\begin{array}{l}\text { Type of } \\
\text { adsorbent }\end{array}$ & Adsorbate & $\begin{array}{l}\text { Initial } \\
\text { concentration } \\
\text { (mg/L) }\end{array}$ & Temp ( $\left.{ }^{\circ} \mathrm{C}\right)$ & $\mathrm{pH}$ & Adsorption capacity & References \\
\hline 1 & FAG & $\mathrm{Cu}^{2+}$ & $100-160$ & $25-45$ & 6 & $152.3 \mathrm{mg} / \mathrm{g}$ & {$[87]$} \\
\hline 2 & FAG & $\mathrm{Ni}^{2+}$ & - & 25 & 5 & approx. 16\% & {$[90]$} \\
\hline 3 & FAG & $\mathrm{Pb}^{2+}$ & - & 25 & 5 & approx. 80\% & {$[90]$} \\
\hline 4 & FAG & $\mathrm{Cu}^{2+}$ & - & 25 & 5 & approx. 29\% & {$[90]$} \\
\hline 5 & FAG & $\mathrm{Cd}^{2+}$ & - & 25 & 5 & approx. 21\% & {$[90]$} \\
\hline 6 & FAG & $\mathrm{Cu}^{2+}$ & - & - & - & $40 \mathrm{mg} / \mathrm{g}$ & {$[104]$} \\
\hline 7 & FAG & $\mathrm{Pb}^{2+}$ & $100-600$ & - & 3 & $24.6-118.6 \mathrm{mg} / \mathrm{g}$ & {$[105]$} \\
\hline 8 & FAG & $\mathrm{Cu}^{2+}$ & - & $30-40$ & - & $90-92 \mathrm{mg} / \mathrm{g}$ & {$[107]$} \\
\hline 9 & FAG & $\mathrm{Pb}^{2+}$ & 100 & $20-45$ and $2 \mathrm{~h}$ & 5 & 174.34 mg/g (90.66\%) & {$[108]$} \\
\hline 10 & FAG & $\mathrm{Cd}^{2+}$ & - & - & - & 26.246 mg/g & [109] \\
\hline
\end{tabular}

it was used as a water softening agent for treatment of hardness causing calcium and magnesium $(\mathrm{Ca}$ (II) and $\mathrm{Mg}(\mathrm{II}))$ as of water [116]. At $\mathrm{pH} 4$ and a contact duration of $24 \mathrm{~h}$, a fly ash/slag-modified geopolymer produced by hydrothermal process demonstrated an adsorption capacity of $15.24 \mathrm{mg} / \mathrm{g}$ for the removal of Cs+ions (96\%) from wastewater [117]. The adsorption capabilities of zinc and nickel cations for metakaolin-based 
geopolymers were $74.53 \mathrm{mg} / \mathrm{g}$ and $42.61 \mathrm{mg} / \mathrm{g}$, respectively. [118]. It was observed that the adsorption was greater at $25{ }^{\circ} \mathrm{C}$. This study investigated the effectiveness of a slag-based geopolymer synthesized from LD slag (Linz Donawitz converter slag) for nickel removal. It was shown to be more efficient than raw LD slag $(14.72 \mathrm{mg} / \mathrm{g})$, with an adsorption capacity of $85.29 \mathrm{mg} / \mathrm{g}$. The optimal adsorption rate was achieved with an initial $\mathrm{Ni}^{2+}$ concentration of $175 \mathrm{mg} / \mathrm{L}$ at $318 \mathrm{~K}$ and $\mathrm{pH} 10$ [119], and the conditions were as follows: Using metakaolin and sodium alginate (1:0.16), a geopolymer hybrid sphere with an interior honeycomb structure was created, and it demonstrated enhanced adsorption capacity of geopolymers $(60.8 \mathrm{mg} / \mathrm{g})$ for $\mathrm{Cu}^{2+}$ ions [120]. A fly ash geopolymer monolith was synthesized by using $67 \%$ of metakaolin and $33 \%$ of biomass fly ash illustrated sorption capacity of $6.3 \mathrm{mg} / \mathrm{g}$ for lead. It was also concluded that porosity greater than 78.4 per cent may improve the removal effectiveness and rate of adsorption [121]. The metakaolin and natural clinoptilolite zeolite were used in different proportions to prepare MK 100 (100\% metakaolin), MK 75 (3:1 ratio of metakaolin with zeolite), MK 50 (1:1 ratio of metakaolin with zeolite) and MK25 (3:1 ratio of metakaolin with zeolite) geopolymers for heavy metal remediation. The MK100 and MK75 showed better removal of $\mathrm{Pb}(\mathrm{II})$ and $\mathrm{Cd}(\mathrm{II})$ than MK50 and MK25 [122]. $\mathrm{Cu}^{2+}, \mathrm{Pb}^{2+}$, and $\mathrm{Ca}^{2+}$ were removed with sorption efficiencies of $34.5,45.1$, and $24.0 \mathrm{mg} / \mathrm{g}$ by using metakaolin-modified porous geopolymer produced by solidification of suspension [123]. The fly ash geopolymer via fly ash with zeolite was employed and for the removal of cadmium with capacity of $26.246 \mathrm{mg} / \mathrm{g}$ [109]. Metakaolin geopolymer impregnated with nanoporous iron-oxide $\left(\mathrm{Fe}_{2} \mathrm{O}_{3}\right)$ showed good adsorption efficiency of $95 \mu \mathrm{g} / \mathrm{g}$ for arsenic as of groundwater [124]. A geopolymeric membrane was developed and used for remediation of heavy metals as well as some more impurities from wastewater [125]. Metakaolin geopolymer was prepared by metakaolin and fume of silica and tested for the elimination of single with multi-components of heavy metals containing solutions [126]. Metakaolin-fly ash geopolymer illustrated sorption efficiency of 85.68, 58.76, and $113.26 \mathrm{mg} / \mathrm{g}$ for $\mathrm{Co}(\mathrm{II}), \mathrm{Sr}(\mathrm{II})$ and $\mathrm{Cs}(\mathrm{I})$ as of aqueous solutions [127].

By employing a unique synthesis method including the use of cetyltrimethylammonium bromide (CTAB) as an organic modifier, a metakaolin mesoporous geopolymer (GP-CTAB) for copper and chromium cation removal was investigated. The exclusion of metal cations and anions by GP-CTAB in an aqueous solution was investigated using this catalyst. The findings revealed that GP-CTAB outperforms other geopolymers that have been employed in the previous studies.
For $\mathrm{Cu}(\mathrm{II})$ and $\mathrm{Cr}(\mathrm{VI})$, the highest adsorption capacity of the GP-CTAB was determined to be $108.2 \mathrm{mg} / \mathrm{g}$ and $95.3 \mathrm{mg} / \mathrm{g}$, respectively, in a binary system [128]. The elimination of ions of heavy metal using adsorbents other than fly ash-based geopolymers is given in Table 3.

However, these geopolymers showed less potential for some metallic cations but structural modifications and optimization of experimental conditions can help in achieving the best results. If we compare the values of adsorption capacities in Tables 2 and 3, it is observed that fly ash-based geopolymers exhibit comparable removal efficiencies to other adsorbents used in water treatment processes. Fly ash geopolymers have proved its efficacy for the removal of lead, copper, zinc, nickel, etc. Since fly ash-based geopolymers are easy to synthesize, convenient to handle, low in cost, non-toxic to environmental components, and better substitutes to expensive zeolites and resins. Thus, fly ash-based geopolymers may serve as a better choice in the said field by exploring more capabilities for the heavy metal removal and other impurities also.

\section{Mechanism of adsorption using isotherms, kinetics and thermodynamics}

Based on the nature of the bonds between the adsorbate and the adsorbent, there are two types of adsorption: physisorption and chemisorption. Physical forces and chemical bonds bind the adsorbate to the adsorbent surface via physisorption and chemisorption, respectively. Ion exchange, complexation, electrostatic attraction, chelation, microprecipitation, hydrophobic bonding, ion pairing, hydrogen bonding, and dispersion (Van der Waals) forces are among the mechanisms used to adsorb substances on solid-liquid interfaces [82]. Heavy metal cations are being linked to aluminate tetrahedral units and thus immobilized in the structure of geopolymers via chemical bonding, which is primarily dependent on the replacement of alkali cations.

The adsorption of $\mathrm{SO}_{4}{ }^{2-}$ ions employing geopolymer took place in two steps; (a) adsorption on external surface (b) low diffusion of adsorbate from surface towards inner pores of adsorbent [82]. The adsorption of nickel ions on LD slag-based geopolymer occurred due to generating a large number of calcium ions on the surface of geopolymer adsorbent via direct ion exchange with $\mathrm{Ni}^{2+}$ ions through chemisorption, whereas physisorption also contributed in adsorption process. The surface adsorption of nickel cations was a rate limiting step which may be attributed to chemisorption [82]. The lead adsorption is chemisorption occurred via sharing of electrons between adsorbate and adsorbent [105]. The adsorption of cadmium ions on zeolite-based 
Table 3 Heavy metal removal by using other adsorbents

\begin{tabular}{|c|c|c|c|c|c|c|}
\hline Adsorbent & Adsorbate & $\begin{array}{l}\text { Surface } \\
\text { area }\left(\mathrm{m}^{2} / \mathrm{g}\right)\end{array}$ & Pore size $(\mathrm{nm})$ & $\begin{array}{l}\text { Pore } \\
\text { volume } \\
\left(\mathrm{cm}^{3} / \mathrm{g}\right)\end{array}$ & $\begin{array}{l}\text { Adsorption } \\
\text { capacity }(\mathrm{mg} / \mathrm{g})\end{array}$ & Ref \\
\hline Fly ash/iron ore tailing-based geopolymers & $\mathrm{Cu}^{2+}$ & - & - & - & 113.41 & {$[85]$} \\
\hline \multirow[t]{2}{*}{ Metakaolin geopolymer } & $\mathrm{CO}^{2+}$ & 39.24 & - & - & 69.23 & [113] \\
\hline & $\mathrm{Mn}^{2+}$ & & & & 72.34 & \\
\hline Metakaolin-based geopolymer modified with CTAB & $\mathrm{Cu}^{2+}$ & 216 & 6 & 0.22 & 40 & [115] \\
\hline Fly ash/slag-based geopolymers & $\mathrm{Cs}^{+}$ & 114.16 & 8.98 & 0.267 & 15.24 & [117] \\
\hline Metakaolin geopolymer (MKG) & $\mathrm{Zn}^{2+}$ & - & - & - & 74.53 & [117] \\
\hline \multirow[t]{2}{*}{ Metakaolin-based geopolymer } & $\mathrm{Zn}^{2+}$ & 39.24 & - & - & 74.53 & [118] \\
\hline & $\mathrm{Ni}^{2+}$ & & & & 42.61 & \\
\hline Geopolymer/Alginate hybrid & $\mathrm{Cu}^{2+}$ & - & - & - & 60.8 & [120] \\
\hline Metakaolin-clinoptilolite zeolite-based geopolymer (MK75) & $\mathrm{Pb}^{2+}$ & - & - & - & 261.2 & [122] \\
\hline Geopolymer microspheres & $\mathrm{Pb}^{2+}$ & 100.99 & 7 & - & 629.21 & [123] \\
\hline Rice husk/metakaolin-based geopolymer & $\mathrm{Cs}^{+}$ & - & - & - & 50.8 & [126] \\
\hline Metakaolin geopolymer spheres & $\mathrm{Cu}^{2+}$ & 53.95 & 5.38 & 0.061 & 52.63 & [129] \\
\hline Metakaolin geopolymers & $\mathrm{NH}_{4}^{+}$ & 22.4 & 30.97 & 0.173 & 21.07 & [130] \\
\hline Metakaolin geopolymer & $\mathrm{NH}_{4}^{+}$ & 19.3 & 30.3 & 0.147 & 19.7 & [131] \\
\hline Acid-treated fly ash & $\mathrm{Cu}^{2+}$ & - & - & - & 207.3 & [132] \\
\hline Multiwalled carbon nanotubes & $\mathrm{Cu}^{2+}$ & - & - & - & 50.3 & [133] \\
\hline Activated carbon & $\mathrm{Cu}^{2+}$ & - & - & - & 43.47 & [134] \\
\hline Composite Chitosan & $\mathrm{Ni}^{2+}$ & - & - & - & 78.10 & [135] \\
\hline Orange peel & $\mathrm{Ni}^{2+}$ & - & - & - & 62.89 & [136] \\
\hline Natural Bentonite & $\mathrm{Ni}^{2+}$ & - & - & - & 50.00 & [137] \\
\hline Na-P Zeolite & $\mathrm{NH}_{4}^{+}$ & - & - & - & 73.8 & [138] \\
\hline Zeolite X & $\mathrm{NH}_{4}^{+}$ & - & - & - & 24.30 & [139] \\
\hline Natural Bentonite & $\mathrm{Zn}^{2+}$ & - & - & - & 52.91 & [140] \\
\hline Acid-treated coconut shell activated carbon & $\mathrm{Zn}^{2+}$ & - & - & - & 45.14 & [141] \\
\hline Geopolymer microspheres & $\mathrm{Pb}^{2+}$ & - & - & - & 629.21 & [142] \\
\hline Sepiolite & $\mathrm{Pb}^{2+}$ & - & - & - & 185.2 & [143] \\
\hline Algae marine, non-living biomass & $\mathrm{Pb}^{2+}$ & - & - & - & 126.5 & [144] \\
\hline Montmorillonite-prussian blue hybrid & $\mathrm{Cs}^{+}$ & - & - & - & 57.47 & [145] \\
\hline Surface-modified sewage sludge molten slag & $\mathrm{Cs}^{+}$ & - & - & - & 52.36 & [146] \\
\hline Concn. nitric acid-modified bamboo charcoal & $\mathrm{Cs}^{+}$ & - & - & - & 45.87 & [147] \\
\hline
\end{tabular}

geopolymer (ZFA) took place through chemisorption mechanism [109]. The removal of Cs(I) ions employing mesoporous geopolymer consisting nanocrystalline zeolite took place via both modes, i.e. physisorption and chemisorption well fitted for multilayer adsorption [117]. Adsorption of copper cations $\mathrm{Cu}$ (II) on metakaolin-sodium alginate hybrid geopolymer happened through chemical bonds formation between adsorbent and adsorbate [120].

Adsorption isotherms are the parameters which gives information about the interactions between the contaminated solution (adsorbate) and the material used as an adsorbent and removal efficiencies [131, 148].

Understanding adsorption kinetics is crucial for determining the rate of adsorption. To investigate the sorption mechanism, many kinetic models have been employed to analyse experimental results. The adsorption kinetics are calculated using a number of models, including pseudo-first order, pseudo-second order, intra-particle diffusion model, and Elovich models. The adsorption rate is proportional to the number of active adsorption sites on the adsorbent in the pseudofirst-order model, which assumes physisorption. The pseudo-second-order model assumes the chemisorption and covers the rate-determining phase of the adsorption process as well as the nature of the bonds that exist between the adsorbate and the adsorbent. The Langmuir isotherm model with pseudo-secondorder kinetics best fits the adsorption of heavy metals 
utilizing geopolymers, whereas the other models fit in an average manner [149].

Adsorption of heavy metal cations employing geopolymers is a chemisorption or/and physisorption, spontaneous, endothermic, and entropy driven process. The variation of $\Delta G^{\circ}$ with increase in temperature determines the temperature effect on adsorption process [82].

\subsection{Adsorption isotherms}

Langmuir and Freundlich adsorption isotherm models are used to optimize and evaluate adsorption behavioural processes and circumstances.

- The Langmuir model predicts the presence of homogeneous adsorption sites and the formation of monolayers devoid of any interactions between the adsorbed substances on their own heavy metal cations. [149]. The relative parameters of this model are calculated using the following equation:

$$
C_{\mathrm{e}} / Q_{\mathrm{e}}=C_{\mathrm{e}} / Q_{0}+1 / Q_{0} b
$$

where $Q_{\mathrm{e}}(\mathrm{mg} / \mathrm{g})$ is amount adsorbed at equilibrium, and

$C_{\mathrm{e}}(\mathrm{mg} / \mathrm{l})$ is equilibrium concentration.

A linear plot of $C_{\mathrm{e}} / Q_{\mathrm{e}}$ against $C_{\mathrm{e}}$ confirms the validity of Langmuir isotherm model for each metal cation. The maximum amount of adsorption capacity, $Q_{0}(\mathrm{mg} / \mathrm{g})$, and energy of adsorption $b$ are Langmuir constants are estimated as the slope and intercept of the plots, respectively.

The dimensionless constant separation factor $R_{\mathrm{L}}$ calculated from the equation given as follows:

$$
R_{\mathrm{L}}=1 /\left(1+b C_{0}\right)
$$

where $C_{0}$ is the ionic concentration capacity.

$R_{\mathrm{L}}$ is the essential characteristics of Langmuir isotherm with the value in between 0 and 1 envisages the spontaneity of the adsorption process [114]. The dimensionless separation factor $R_{\mathrm{L}}$ has the following four key inferences. When $0<R_{\mathrm{L}}<1$, it represents a favourable

Table 4 Langmuir model adsorption isotherm parameters for $\mathrm{Cu}^{2+}[104]$

\begin{tabular}{lllll}
\hline Samples & Alkali activation & $\begin{array}{l}\text { Adsorption } \\
\text { capacity } \\
\boldsymbol{q}_{\text {max }}(\mathbf{m g} / \mathbf{g})\end{array}$ & $\boldsymbol{K}_{\mathrm{L}}(\mathbf{L} / \mathbf{m g})$ & Langmuir $\left(\boldsymbol{R}^{2}\right)$ \\
\hline $\mathrm{FA}$ & - & 7 & 0.14 & 0.990 \\
$\mathrm{Na}-\mathrm{GP}$ & $\mathrm{NaOH}$ & 30 & 3.18 & 0.992 \\
$\mathrm{~K}-\mathrm{GP}$ & $\mathrm{KOH}$ & 16 & 4.11 & 0.991 \\
$\mathrm{NaSil-GP}$ & $\mathrm{NaOH}+\mathrm{Na}_{2} \mathrm{SiO}_{3}$ & 40 & 0.69 & 0.994 \\
$\mathrm{KSil}-\mathrm{GP}$ & $\mathrm{KOH}+\mathrm{Na}_{2} \mathrm{SiO}_{3}$ & 28 & 0.76 & 0.993 \\
\hline
\end{tabular}

isotherm connoting successful and efficient interaction between adsorbate and adsorbent. If $R_{\mathrm{L}}>1$, it depicts unfavourable isotherm. When $R_{\mathrm{L}}=0$, it embodies an irreversible isotherm, and finally, when $R_{\mathrm{L}}=1$, it shows a linear isotherm.

- In the Freundlich model, adsorption occurs on a heterogeneous surface adsorbent with uneven distribution of active sites for adsorption [108, 149], and the adsorption process is described as follows: In nonideal adsorption processes, active sites with nonequivalent energies and the formation of multilayers on the surface of the adsorbent material are characteristics that can be described. [117].

The linearized form of Freundlich isotherm model is represented by the following equation:

$$
\ln Q_{\mathrm{e}}=\ln K_{\mathrm{F}}+1 / n \ln C_{\mathrm{e}}
$$

where $Q_{\mathrm{e}}(\mathrm{mg} / \mathrm{g})$ and $C_{\mathrm{e}}(\mathrm{mg} / \mathrm{L})$ stand for adsorption capacity of adsorbent and concentration of adsorbate, respectively, at equilibrium. The $n$ and $K_{\mathrm{F}}$ are Freundlich model constants indicative of intensity and adsorption capacity, respectively, where $n$ represents the surface heterogeneity or magnitude of adsorption driving force. A plot of $\log Q_{\mathrm{e}}$ versus $\log C_{\mathrm{e}}$ would result in a straight line with a slope of $(1 / n)$ and intercept of $\ln K_{\mathrm{F}}$. When $1 / n>1$, co-adsorption ensues while a normal L-type is epitomized when $1 / n<1$ [114].

Table 5 Freundlich model adsorption isotherm parameters for $\mathrm{Cu}^{2+}[104]$

\begin{tabular}{lllcl}
\hline Samples & Alkali activation & $\boldsymbol{n}$ & $\begin{array}{c}\boldsymbol{K}_{\mathbf{F}}(\mathbf{( m g / g )} \\
\left.(\mathbf{L} / \mathbf{m g})^{\mathbf{1 / n}}\right)\end{array}$ & Freundlich $\left(\boldsymbol{R}^{\mathbf{2}}\right)$ \\
\hline $\mathrm{FA}$ & - & 3.03 & 1.73 & 0.867 \\
$\mathrm{Na}-\mathrm{GP}$ & $\mathrm{NaOH}$ & 4.22 & 16.81 & 0.866 \\
$\mathrm{~K}-\mathrm{GP}$ & $\mathrm{KOH}$ & 6.29 & 9.58 & 0.865 \\
$\mathrm{NaSil}-\mathrm{GP}$ & $\mathrm{NaOH}+\mathrm{Na}_{2} \mathrm{SiO}_{3}$ & 2.44 & 14.74 & 0.973 \\
KSil-GP & $\mathrm{KOH}+\mathrm{Na}_{2} \mathrm{SiO}_{3}$ & 3.15 & 11.41 & 0.942 \\
\hline
\end{tabular}

Table 6 Temkin model adsorption isotherm parameters for $\mathrm{Cu}^{2+}$ [104]

\begin{tabular}{lllcl}
\hline Samples & Alkali activation & $\boldsymbol{B}_{\mathbf{T}}(\mathbf{J} / \mathbf{m o l})$ & $\boldsymbol{A}_{\mathbf{T}}(\mathbf{L} / \mathbf{g})$ & Temkin $\left(\boldsymbol{R}^{\mathbf{2}}\right)$ \\
\hline $\mathrm{FA}$ & - & 1.49 & 0.35 & 0.920 \\
$\mathrm{Na}-\mathrm{GP}$ & $\mathrm{NaOH}$ & 4.71 & 18.66 & 0.921 \\
$\mathrm{~K}-\mathrm{GP}$ & $\mathrm{KOH}$ & 1.75 & 10.29 & 0.892 \\
$\mathrm{NaSil}-\mathrm{GP}$ & $\mathrm{NaOH}+\mathrm{Na}_{2} \mathrm{SiO}_{3}$ & 1.75 & 10.29 & 0.892 \\
KSil-GP & $\mathrm{KOH}+\mathrm{Na}_{2} \mathrm{SiO}_{3}$ & 5.1 & 12.57 & 0.975 \\
\hline
\end{tabular}


- Tables 4, 5 and 6 contain the isotherms and their fitted models, as well as the parameters that were derived from them [104]. $R^{2}$ was found to be the greatest (closest to unity) correlation coefficient for each of the isotherms, indicating that each isotherm preferred the Langmuir model. The highest adsorption capabilities of the geopolymers were found to be in the following order: $40 \mathrm{mg} / \mathrm{g}(\mathrm{NaSil}-\mathrm{GP})>30 \mathrm{mg} / \mathrm{g}$ $(\mathrm{Na}-\mathrm{GP})>28 \mathrm{mg} / \mathrm{g}(\mathrm{KSil}-\mathrm{GP})>16 \mathrm{mg} / \mathrm{g}(\mathrm{K}-\mathrm{GP})$ and $7 \mathrm{mg} / \mathrm{g}$ (K-GP), respectively (FA).

According to the results, the adsorption of $\mathrm{Cu}^{2+}$ from wastewater on geopolymer adsorbent based on fly ash followed the Langmuir isotherm with a separation factor smaller than one, which was determined to be favourable. The monolayer adsorption was carried out in accordance with a pseudo-second-order model, with chemisorption serving as the rate-determining step. The Langmuir model was tested at three different temperatures $(25,35$, and $45^{\circ} \mathrm{C}$ ), and at $\mathrm{pH}$ levels ranging from 4 to 6 . The values of correlation coefficients $\left(R^{2}\right)$ were observed between 0.973 and 0.994 , and the highest adsorption capacity was $152.3 \mathrm{mg} / \mathrm{g}(2.38 \mathrm{mmol} / \mathrm{g})$ at $\mathrm{pH} 6$ and $45^{\circ} \mathrm{C}$. The values of $R^{2}$ for Freundlich model were between 0.944 and 0.993 at the conditions used in Langmuir model [87].

As a result of the high fitting coefficients, both the Freundlich and the Langmuir models were able to accurately predict the adsorption behaviour of copper ions from wastewater utilizing fly ash-iron ore tailing-based porous geopolymer. At $40{ }^{\circ} \mathrm{C}$ and $\mathrm{pH} 6$, the maximum adsorption capacity and correlation coefficient values were 0.9897 and $113.41 \mathrm{mg} / \mathrm{g}$, respectively [85]. In this study, the Langmuir and Freundlich models for understanding cadmium adsorption behaviour on fly ash-based geopolymer were evaluated to see how well they performed. Using adsorbate starting concentrations ranging from 10 to $120 \mathrm{mg} / \mathrm{L}$, the Langmuir and Freundlich models were tested at $25{ }^{\circ} \mathrm{C}$ and $\mathrm{pH} 5.0 .970$ and 0.916 , respectively, for the Langmuir and Freundlich equations in terms of the correlation coefficient $\left(R^{2}\right)$, the findings indicated that Langmuir model is more accurate for the monolayer adsorption of cadmium on geopolymer than the Freundlich model for this application. From high $R^{2}$ values, both Langmuir and Freundlich models could describe the adsorption of $\mathrm{Cd}^{2+}$ on geopolymer adsorbent particles. Adsorption capacity of geopolymer particles made from fly ash was $9.017 \mathrm{mg} / \mathrm{g}$ for the $\mathrm{Cd}^{2+}$ ions, which was the highest value found in the study. Furthermore, $n>1$ exhibited preferential adsorption on an adsorbent [90, 150].

Using aqueous solutions, researchers investigated the adsorption of lead, discovering that the greatest adsorption capacity was $6.34 \mathrm{mg} / \mathrm{g}$. Using adsorption behaviour of lead from aqueous medium as a starting point, it was discovered that lead ions were removed at a considerable rate of $97.7 \%$. For explaining the adsorption mechanism of $\mathrm{Pb}^{2+}, \mathrm{Cd}^{2+}, \mathrm{Cu}^{2+}$, and $\mathrm{Ni}^{2+}$ ions, the Langmuir model performed better than the Freundlich model, with correlation coefficients above $0.960,0.985,0.982$, and 0.927 , respectively. It was discovered that monolayer adsorption, comprising chemisorption mechanisms and electrostatic attractions, was constrained by the acquired findings [150].

As a result of the better fit of the Langmuir model obtained in majority of the studies, it can be inferred that heavy metal ion adsorption onto the geopolymer adsorbent is classified as monolayer.

\subsection{Adsorption kinetics}

Adsorption kinetics gives an insight to comprehend the adsorption rate. Models as pseudo-first order, pseudosecond order, Elovich models and so on are examples of these types of models and intra-particle diffusion model have been used for determining the kinetics involved in adsorption. According to pseudo-first-order model, adsorption rate is directly proportional to the number of active adsorption sites available on the surface of adsorbent. This model, known as the pseudo-second-order model, focuses on the rate-determining phase of adsorption as well as the several kinds of chemical bonding between the sample adsorbate and the synthesized adsorbent. The linearized forms of pseudo-first-order (PFO) and pseudo-second-order (PSO) kinetic equations are given as follows:

$$
\begin{array}{ll}
\ln \left(Q_{\mathrm{e}}-Q_{t}\right)=\ln Q_{\mathrm{e}}-\left(k_{1} / 2.303\right) t & \text { PFO kinetic equation } \\
t / Q_{\mathrm{t}}=1 / k_{2} Q_{\mathrm{e}}^{2}+\left(1 / Q_{\mathrm{e}}\right) t & \text { PSO kinetic equation }
\end{array}
$$

where $Q_{\mathrm{e}}$ and $Q_{t}$ represent metal ion adsorbed per unit weight of adsorbent (in $\mathrm{mg} / \mathrm{g}$ ) at equilibrium at time $t$, respectively, and $k_{1}$ and $k_{2}$ stand for PFO and PSO rate constants, respectively [114].

With respect to adsorption of toxic heavy metals utilizing various geopolymers, the Langmuir model with pseudo-second-order kinetics is usually more accurate than other models $[119,130]$. According to another study, nonlinear regression was used to evaluate Lagergren pseudo-first-order, pseudo-second-order (Ho), and Elovich models using nonlinear regression techniques. The Ho model, which was evaluated in order to explain the adsorption of copper from wastewater samples using a fly ash-based geopolymer, had the best match of all the kinetic models studied. It was stated that the values of correlation coefficients $\left(R^{2}\right)$ in the Ho model were greater than those in other models that were used to describe the adsorption of copper on fly ash-based geopolymer, which was a pseudo-second-order process [101]. 
Sample adsorbate is immobilized onto surface of adsorbent, physical forces are involved in physisorption, and chemical bonds are involved in chemisorption. Electrostatic attraction, ion exchange, ion pairing, hydrophobic bonding, hydrogen bonding, and dispersion (Van der Waals) forces are involved in physisorption and chemisorption, respectively. [151]. The adsorption mechanism of lead $(\mathrm{Pb}(\mathrm{II}))$ is a chemisorption occurring via sharing of electrons between adsorbate and the adsorbent surface [142]. This study summarized adsorption behaviour of heavy metal ions using alkali-activated fly ash-based geopolymers. It was concluded that experimental findings fitted best in the pseudo-second-order model because its $R^{2}$ values were closer to unity in comparison to pseudofirst-order model. So, adsorption followed the pseudosecond-order model in which the chemisorption is the key driven force (Table 7) [104].

\subsection{Adsorption thermodynamics}

Thermodynamic functions like enthalpy or heat of adsorption $\left(\Delta H^{\circ}\right)$, Gibbs free energy of adsorption $\left(\Delta G^{\circ}\right)$, and standard entropy changes $\left(\Delta S^{\circ}\right)$ describe about adsorption and disorderness or randomness of the system at liquid-solid interface and are calculated using the following equations:

$$
\begin{aligned}
& K_{\mathrm{c}}=C_{0}-C_{\mathrm{e}} / C_{\mathrm{e}} \\
& \Delta G^{\circ}=-R T \ln K_{\mathrm{c}} \\
& \ln K_{\mathrm{c}}=-\Delta G^{\circ} / R T \\
& \ln K_{\mathrm{c}}=\Delta S^{\circ} / R-\Delta H^{\circ} / R T
\end{aligned}
$$

where $K_{\mathrm{c}}$ is the thermodynamic equilibrium constant, $\Delta G$ is the Gibbs free energy change, $\Delta S$ is the entropy change $(\mathrm{J} / \mathrm{mol}), \Delta H$ is the enthalpy change $(\mathrm{J} / \mathrm{mol}), R$ is the universal gas constant $(8.314 \mathrm{~J} / \mathrm{mol} \mathrm{K})$ and $T$ is the absolute temperature in Kelvin (K). The slope and intercept of the plot of $\ln K_{\mathrm{C}}$ versus $1 / T$ give $\Delta H^{\circ}$ and $\Delta S^{\circ}$ [114].

The positive (+ve) and negative ( - ve) values of $\Delta G^{\circ}$ showed about the spontaneity and nonspontaneity of the adsorption reaction. The enthalpy $\left(\Delta H^{\circ}\right)$ values, less than and greater than $21 \mathrm{~kJ} / \mathrm{mol}$, describes physisorption and chemisorption [105]. The entropy $\left(\Delta S^{\circ}\right)$ values with plus sign are indicative of increase in disorder at the interface during adsorption. Thermodynamic functions are determined by using three constants such as partition constant, distribution constant, and isotherm constant. The positive values of $\Delta H^{\circ}$ and $\Delta S^{\circ}$ indicate adsorption as endothermic and irreversible [114, 152]. As a result, heavy metal adsorption on geopolymers is found to be chemisorption or physisorption, spontaneous, endothermic, and entropy driven process. The varying $\Delta G^{\circ}$ values with increasing temperature are a deciding factor for optimization of adsorption rate in heavy metal remediation.

The $\Delta G^{\circ}, \Delta H^{\circ}$ and $\Delta S^{\circ}$ values for adsorption of lead ions on porous geopolymer microspheres at $25{ }^{\circ} \mathrm{C}$ were found to be $-20.138 \mathrm{~kJ} / \mathrm{mol}, 23.86 \mathrm{~kJ} / \mathrm{mol} \mathrm{K}, 0.15 \mathrm{~J} / \mathrm{mol}$ [142]. The $\Delta H^{\circ}$ and $\Delta S^{\circ}$ values for copper adsorption were found to be positive while $\Delta G^{\circ}$ values decreased with an increase in temperature, which suggested endothermic behaviour of adsorption. The negative values of $\Delta G^{\circ}$ at different temperatures attributed spontaneity to the adsorption. The $\Delta S^{\circ}$ positive values indicated the increased disorderness of the system because adsorption of copper ions on the surface of geopolymer led to the separation of hydrated water molecules prior they bind to the adsorbent surface thereby increased randomness of the system $\left(\Delta G^{\circ}-23.09 \mathrm{~kJ} / \mathrm{mol}, \Delta H^{\circ} 39.49 \mathrm{~kJ} / \mathrm{mol}, \Delta S^{\circ}\right.$ $196.78 \mathrm{~J} / \mathrm{mol} \mathrm{K}, R^{2} 0.984$ at $\mathrm{pH} 6$ and $45^{\circ} \mathrm{C}$ ) [87].

The values observed for thermodynamic parameters and correlation coefficient were $\Delta G^{\circ}-26.70 \mathrm{~kJ} / \mathrm{mol}$, $\Delta H^{\circ} 40.38 \mathrm{~kJ} / \mathrm{mol}, \Delta S^{\circ} 205.92 \mathrm{~J} / \mathrm{mol} \mathrm{K}, R^{2} 0.9823$ at $\mathrm{pH}$ 6 and $45{ }^{\circ} \mathrm{C}$ for copper adsorption from wastewater on fly ash-iron ore tailing-based geopolymers. The copper adsorption on alkali-activated geopolymers was endothermic in nature assigned to positive values of standard enthalpy. The positive values of standard entropy indicate the rising disorderness on solid-liquid interface and all

\begin{tabular}{|c|c|c|c|c|c|c|}
\hline \multirow[t]{2}{*}{ Samples } & \multicolumn{3}{|c|}{ Pseudo-first order } & \multicolumn{3}{|c|}{ Pseudo-second order } \\
\hline & $q_{\mathrm{e}}(\mathrm{mg} / \mathrm{g})$ & $k_{1}($ per min) & $R^{2}$ & $q_{\mathrm{e}}(\mathrm{mg} / \mathrm{g})$ & $k_{2}(\mathrm{~g} / \mathrm{mg} / \mathrm{min})$ & $R^{2}$ \\
\hline FA & 8.31 & 0.35 & 0.952 & 8.49 & 0.07 & 0.994 \\
\hline $\mathrm{Na}-\mathrm{GP}$ & 29.95 & 0.23 & 0.930 & 32.39 & 0.01 & 0.990 \\
\hline K-GP & 23.97 & 0.07 & 0.960 & 27.29 & 0.03 & 0.995 \\
\hline NaSil-GP & 34.33 & 0.55 & 0.911 & 35.96 & 0.03 & 0.991 \\
\hline KSil-GP & 27.67 & 0.32 & 0.959 & 29.5 & 0.02 & 0.992 \\
\hline
\end{tabular}
geopolymers displayed negative values of $\Delta G^{\circ}$ affirming spontaneous adsorption of copper ions (Table 8) [104].

Table 7 Parameters of $\mathrm{Cu}^{2+}$ adsorption kinetics [104] 
Table 8 Parameters of $\mathrm{Cu}^{2+}$ adsorption thermodynamics [104]

\begin{tabular}{|c|c|c|c|c|c|}
\hline Samples & Alkali activation & Temperature $T(\mathrm{~K})$ & $\Delta G^{\circ}(\mathrm{kJ} / \mathrm{mol})$ & $\Delta H^{\circ}(\mathrm{kJ} / \mathrm{mol})$ & $\Delta S^{\circ}(\mathrm{J} / \mathrm{mol} \mathrm{K})$ \\
\hline \multirow[t]{3}{*}{ FA } & - & 298 & -32.00 & 6.18 & 128.11 \\
\hline & & 313 & -34.51 & & \\
\hline & & 333 & -36.49 & & \\
\hline \multirow[t]{3}{*}{$\mathrm{Na}-\mathrm{GP}$} & $\mathrm{NaOH}$ & 298 & -39.38 & 8.12 & 159.39 \\
\hline & & 313 & -42.57 & & \\
\hline & & 333 & -44.96 & & \\
\hline \multirow[t]{3}{*}{ K-GP } & $\mathrm{KOH}$ & 298 & -37.31 & 8.05 & 152.20 \\
\hline & & 313 & -40.35 & & \\
\hline & & 333 & -42.63 & & \\
\hline \multirow[t]{3}{*}{ NaSil-GP } & $\mathrm{NaOH}+\mathrm{Na}_{2} \mathrm{SiO}_{3}$ & 298 & -36.57 & 9.97 & 156.15 \\
\hline & & 313 & -39.69 & & \\
\hline & & 333 & -42.03 & & \\
\hline \multirow[t]{3}{*}{ KSil-GP } & $\mathrm{KOH}+\mathrm{Na}_{2} \mathrm{SiO}_{3}$ & 298 & -36.37 & 8.16 & 149.42 \\
\hline & & 313 & -39.36 & & \\
\hline & & 333 & -41.60 & & \\
\hline
\end{tabular}

In accordance with the review of literature available, it may be stated that Langmuir's isotherm models and Freundlich's isotherm models better represented the sorption process, signalling monolayer and multilayer sorptions. Both exothermic and endothermic processes showed the nature of the thermodynamic process during sorption, and the pseudo-second-order (PSO) model offered the best suited way of explaining the kinetic process.

\section{Factors affecting adsorption process of heavy metals using fly ash-based adsorbents}

Adsorption process is influenced by some factors such as $\mathrm{pH}$, adsorbent dosage, temperature, contact time, IConc, amount of volume treated, particle size, adsorption system type, and co-existing ions, and the physico-chemical characteristics of absorbent (like chemical, biochemical, and functionality. These parameters greatly affect the performance of adsorbents while removing heavy metal ions.

According to Darmayanti et al. [104], pH of a solution has an effect on the surface charge of the solution, the degree of ionization, and the adsorbate species present in solution. The majority of the metal adsorbed increases with rising $\mathrm{pH}$ of the solution until a certain point, beyond which it decreases if the $\mathrm{pH}$ of the solution is increased further. When it comes to $\mathrm{pH}$, the equation may be expressed as:

$$
\mathrm{pH}=p k_{a}-\log \left[\mathrm{A}^{-}\right] /[\mathrm{HA}]
$$

where $\left[\mathrm{A}^{-}\right]$and $[\mathrm{AH}]$ indicate the concentration of deprotonated and protonated surface groups, and the equilibrium constants matched those of the carbonyl groups, respectively.

The findings indicated that the adsorption efficiency improves from 4.9 to $93.5 \%$ when the $\mathrm{pH}$ is changed from 1 to 5 , but decreases when the $\mathrm{pH}$ is increased to 6 . Therefore, $\mathrm{pH} 5$ is denoted as a charge with no positive or negative ions (Table 9) [85]. In general, it is believed that geopolymer FA is efficient across a broad $\mathrm{pH}$ range, which may be attributed mostly to the porous nature of the material, as previously stated. Excess positive $\mathrm{H}_{3} \mathrm{O}^{+}$ species are accessible in the solution at low alkalinity (low $\mathrm{pH}$ values), and these positive $\mathrm{H}_{3} \mathrm{O}^{+}$species compete with heavy metal positive ions for available adsorption sites on the surface of porous geopolymer. A decrease in $\mathrm{H}_{3} \mathrm{O}^{+}$availability occurs as a result of increasing $\mathrm{pH}$,

Table 9 Langmuir model parameters at varied temperatures and pH [85]

\begin{tabular}{|c|c|c|c|c|c|c|c|c|c|}
\hline \multirow[t]{2}{*}{$T\left({ }^{\circ} \mathrm{C}\right)$} & \multicolumn{3}{|l|}{$\mathrm{pH} 4$} & \multicolumn{3}{|l|}{ pH 5} & \multicolumn{3}{|l|}{$\mathrm{pH} 6$} \\
\hline & $q_{\mathrm{m}}(\mathrm{mg} / \mathrm{g})$ & $K_{\mathrm{L}}(\mathrm{L} / \mathrm{mg})$ & $R^{2}$ & $q_{\mathrm{m}}(\mathrm{mg} / \mathrm{g})$ & $K_{\mathrm{L}}(\mathrm{L} / \mathrm{mg})$ & $R^{2}$ & $\overline{q_{m}(\mathrm{mg} / \mathrm{g})}$ & $K_{\mathrm{L}}(\mathrm{L} / \mathrm{mg})$ & $R^{2}$ \\
\hline 20 & 63.36 & 0.058 & 0.9882 & 69.11 & 0.049 & 0.9859 & 81.55 & 0.60 & 0.9936 \\
\hline 30 & 65.80 & 0.066 & 0.9850 & 83.31 & 0.055 & 0.9915 & 93.50 & 0.069 & 0.9950 \\
\hline 40 & 79.31 & 0.064 & 0.9793 & 100.82 & 0.069 & 0.9890 & 113.41 & 0.073 & 0.9897 \\
\hline
\end{tabular}


which allows heavier metal ions to more readily reach heavy metal adsorbents [104].

From different reported researches, it is ascertained that the solution of $\mathrm{pH}$ has a noticeable impact on heavy metal adsorption on various adsorbents along with geopolymers. Within specific $\mathrm{pH}$ range, adsorption of heavy metals upsurges with increasing $\mathrm{pH}$ values up to a optimum mark but after then adsorption efficiency reduces with a further rise in $\mathrm{pH}$ value. Hence, $\mathrm{pH}$ effect could also be defined in terms of $\mathrm{pH}$ at point of zero (nil) charge, at which charge on the surface of the adsorbent is at nil charge [118].

Kara et al. [113] investigated the influence of $\mathrm{pH}$ on geopolymer metal adsorption capability. The adsorption yield of $\mathrm{Mn}$ (II) and $\mathrm{Co}$ (II) ions onto geopolymer rose fast when the $\mathrm{pH}$ value increased from 2.0 to 3.0. The adsorbent's metal adsorption performance did not alter much after that. This finding suggested that $\mathrm{pH}$ might have a significant impact on the adsorption of $\mathrm{Mn}$ (II) and $\mathrm{Co}(\mathrm{II})$ ions onto geopolymer. The zeta potentials at different $\mathrm{pHs}$ aids in demonstrating the effect of $\mathrm{pH}$ on geopolymer adsorption ability. Due to high amounts of $\mathrm{H}^{+}$ions, the geopolymer surface was positive at low $\mathrm{pH}$. The positive feature of geopolymer became neutral or negative when the $\mathrm{pH}$ value was increased. Then, the positive surface diminished electrostatic interactions with metal cations. The repulsive interactions between the geopolymer surface and metal cations enhanced the adsorption yield of geopolymer as $\mathrm{pH}$ rose.

The isoelectric point (IEP) of metakaolin-based geopolymer adsorbent is the solution $\mathrm{pH}$ at which the overall surface charge on geopolymer adsorbent is zero and analyzed by measuring zeta potentials of metakaolin-based geopolymer at varied $\mathrm{pH}$ values of aqueous suspension. IEP of metakaolin-based geopolymer was observed $<\mathrm{pH}$ 2.0. Above $\mathrm{pH}$ values of IEP, the geopolymer surface is negatively charged and thus it electrostatically interacts with metal cations. It was also indicated that "all of the surface charge of metakaolin-based geopolymer in both metal ion solutions was more negative than surface charges measured in aqueous medium at the investigated $\mathrm{pH}$ interval. On the other hand, more negative zeta potentials for metakaolin-based geopolymer were measured in $\mathrm{Mn}(\mathrm{II})$ ion solution. This finding could also be an explanation for slightly higher adsorption yield of $\mathrm{Mn}$ (II) ions than Co(II) ions" [113, 118].

Investigations on intra-particle diffusion have demonstrated that particle dimension of adsorbents apparently influences the degree of adsorption especially for heavy metal cations. Reduction in particle size results in increasing surface area and finally a rise in adsorption possibilities at external surface of the adsorbents. There is also an opportunity for intra-particle diffusion from the external surface of adsorbent into the pores of substance. The adsorption capacity depends on the available specific surface area for the solute interaction of the surface. Many studies have demonstrated that adsorption capacity enhances with a larger surface area. Though conversely, minor particle size upsurges the adsorption capacity. Darmayanti et al. [104] optimized the effect of adsorbent dose on $\mathrm{Cu}^{2+}$ ions removal and concluded that adsorption efficiency increased from 24.90 to $93.90 \%$ for the first FAG and 29.30 to $56.70 \%$ for second FAG upon elevating the adsorbent dose amounts from 1.00 to $10.00 \mathrm{~g} / \mathrm{L}$, respectively. The upsurge was attributed to the rise in surface area and the accessible adsorption sites of FAG. With increasing adsorbent dose, the accessible locations for binding copper $\left(\mathrm{Cu}^{2+}\right)$ ions increase and hence the adsorption efficiency improves.

Onutai and his associates studied the effect of contact time on $\mathrm{Cd}^{2+}$ adsorption and observed that adsorption was increased with a rise in contact time from 0 to $200 \mathrm{~min}(76.33 \%$ in $120 \mathrm{~min})$ [90, 150].

For a given initial concentration of adsorbate components, geopolymer dose is an important factor because it decides adsorbent capacity to uptake adsorbate. When geopolymer dose was increased from 0.02 to $0.14 \mathrm{~g}$, a notable increase in removal efficiency was observed from 33.51 to $84.4 \%$. Increase in dose of geopolymer adsorbent rendered more surface area and adsorption sites for adsorption of $\mathrm{Cd}^{2+}$ ions, resulted in more adsorption capacity $[90,150]$.

After increasing initial concentration from 10 to $120 \mathrm{mg} / \mathrm{L}$, higher removal efficiency was seen $(70 \%)$ at $<20 \mathrm{mg} / \mathrm{L}$ or $\mathrm{ppm}$ due to sufficient available pores and space to adsorb $\mathrm{Cd}^{2+}$ ions in solution. When the initial concentration of adsorbate increases, inadequate availability of binding sites indicates the achievement of saturation level of adsorbent for no more adsorption of heavy metals. Thus, there are still ions which remained in the solution and unable to adsorb onto the surface of adsorbent $[90,150]$.

When $\mathrm{pH}$ value was increased from 1 to 5 , the adsorption efficiency increased from 0 to $76.33 \%$. The excess of positive $\mathrm{H}_{3} \mathrm{O}^{+}$ions in the solution at low $\mathrm{pH}$ values could competition with cadmium ions on available geopolymer surface. Therefore, the adsorption capacity had the lowest value at $\mathrm{pH} 1-2$, but a significant height in adsorption capacity was observed at $\mathrm{pH} 3-5$. Temperature was also found to be having the relevant effect on adsorption of heavy metals using geopolymers. The removal per cent of $\mathrm{Cd}^{2+}$ ions was noted as $76.33,80.69$, and $82.85 \%$ at 25,35 and $45{ }^{\circ} \mathrm{C}$, respectively. At high temperature, the vaporization of water occurred with improved micro-cavities geopolymer sample hence increased adsorption capacity. 
It can be further explained with the help of adsorption thermodynamics. When temperature increases, the thermodynamic parameters, enthalpy $\left(\Delta H^{\circ}\right)$ and entropy $\left(\Delta S^{\circ}\right)$ are + ve while $\Delta G^{\circ}$ is - ve. This implies that endothermic sorption process occurred and is favourable at higher temperature $[90,150]$.

It was also found that powdered porous geopolymer exhibited a much higher removal efficiency $(90.7 \%)$ in comparison to powdered conventional geopolymer. It might be attributed to higher porousness of porous geopolymer resulting in more available binding sites.

$\mathrm{Pb}^{2+}$ was adsorbed the most, among other heavy metal cations like cadmium $(4.26 \AA,-429.8 \mathrm{kcal} / \mathrm{mol})$, copper $(4.19 \AA,-496.9 \mathrm{kcal} / \mathrm{mol})$, and chromium (4.61 , - $1005.5 \mathrm{kcal} / \mathrm{mol})$. This could be attributed to the smaller radii (4.01 $\AA$ ) and higher free energy of hydration $(-357.2 \mathrm{kcal} / \mathrm{mol})$ of $\mathrm{Pb}^{2+}$. Larger the radius of hydrated metal ion, higher the free energy of hydration, and thus more difficulty for the metal cations to be adsorbed, and vice versa.

The binding force of the adsorbate and adsorbent during the adsorption process of heavy metal cations using FA-based adsorbent or other adsorbents is affected by the co-existing ions/ionic strength of a solution. The coexisting ions affect the potential and width of the interface of the dual-layer round the adsorbent. The removal effectiveness of heavy metal cations is degraded significantly with persisting co-existing positively charged ions. Therefore, it is necessary to target particular heavy metal cation for its selective removal efficiently.

It is concluded from different studies that the removal efficiency increased with a rise in geopolymer dosage, $\mathrm{pH}$, contact time, temperature and a decrease in $\mathrm{Cd}^{2+}$ initial concentration and co-existing ions.

\section{Fly ash toxicity and heavy metals leaching in its remediation}

Fly ash is a hazardous waste product that is generated as a by-product of coal combustion in power plants. It has capability to adsorb heavy metal ions, and it is currently being investigated for this purpose. The adsorption ability of fly ash to adsorb $\mathrm{Pb}^{2+}, \mathrm{Cu}^{2+}$, and $\mathrm{Zn}^{2+}$ from wastewater is depending on the varied circumstances of contact duration, $\mathrm{pH}$, and temperature used. It has been discovered that the absorption of metal ions by fly ash increases with increasing $\mathrm{pH}$ [153]. According to the findings, the effluent from wastewater treatment plants that was treated with fly ash had lower heavy metal contents than the control effluent. It was observed that fly ash treatment may reduce metal concentrations by up to $60 \%$, therefore lowering the toxicity of the effluent and reducing the amount of pollution. When coal is burned, fly ash is produced as a waste product [154]. However, it has been proven to be beneficial in the removal of metals from wastewater.

\subsection{Heavy metal leaching in fly ash}

Fly ash contains heavy metals such as As, B, Cd, Cr, Co, $\mathrm{Mo}, \mathrm{Hg}$, Se, $\mathrm{Mn}, \mathrm{Ni}, \mathrm{Pb}, \mathrm{V}$ and $\mathrm{Zn}$, contained in either free-form, surface-linked or complexion-shaped aluminosilicate matrix. Elements have a lower leaching potential than those of surfactant particles [155]. Metal leaching is impacted by $\mathrm{pH}$, leachant type, mixing circumstances, leachage length, temperature and particle size distribution in presence of aqueous medium [156]. It is also thought that significant elements like $\mathrm{Ca}, \mathrm{K}$, $\mathrm{Mg}, \mathrm{Al}$ are more acidic than $\mathrm{Ba}, \mathrm{Cd}, \mathrm{Co}, \mathrm{Cr}, \mathrm{Cu}, \mathrm{Fe}, \mathrm{Na}$, $\mathrm{Mn}, \mathrm{Mo}, \mathrm{Pb}, \mathrm{Th}, \mathrm{Ni}, \mathrm{U}, \mathrm{V}$, and $\mathrm{Zn}$ [157]. The release of cationic species relies on the quantity of $\mathrm{Ca}$. The higher the calcium content, the more acid and the time period for the release of metals will be necessary. Cationic species release relies on the quantity of $\mathrm{Ca}$ concentration. The higher the calcium content the more acid is needed and the longer it takes to liberate metals [158]. The main components of fly ash in nature have been $\mathrm{Ca}, \mathrm{Mg}, \mathrm{Si}, \mathrm{P}$, $\mathrm{Al}, \mathrm{Fe}, \mathrm{Ti}, \mathrm{Na}$ and $\mathrm{K}$. $\mathrm{Ca}$ and $\mathrm{P}$ have been shown to have more leaching capacity, whereas $\mathrm{K}, \mathrm{Fe}$, to produce insoluble stable oxides, has been less leaching [159].

\subsection{Heavy metal leaching with fly ash geopolymeric adsorbents}

Fly ash that has been submerged in water for an extended period of time contains partially seeped agglomerated grains with a bimodal size distribution, according to the findings. For $30 \mathrm{~min}$, grinding of pond ash, an alkaline activation of this material results in the formation of a geopolymer-type binder with high compression strength. In addition to the enhanced reactivity of the finer particles in milled pond ash, there has been an increase in the content and density of the resulting geopolymer binder, which has resulted in increased compression strength. In leaching studies, it has been shown that the presence of hazardous elements ( $\mathrm{As}, \mathrm{Cr}, \mathrm{Pb}$ and $\mathrm{Cr}$, and $\mathrm{Sr}$ ) in the original pond ash does not result in the release of harmful heavy metals from the product under consideration. A further benefit of the combination of grinding and alkali treatment is that it prevents the discharge of dangerous heavy metals from the product, making it appropriate for use in building applications [160].

\section{Regeneration and desorption/recovery studies}

From an economic and environmental standpoint, regeneration is a critical feature of adsorption. It truly answers a variety of queries and concerns about what happens to the adsorbent after adsorption so that the results are not thrown out because the adsorbent may contain harmful 
adsorbates. One of the issues involved with adsorption techniques is adsorbent disposal. Regeneration can lessen the requirement for new adsorbent while also alleviating the problem of adsorbent waste. Around the world, say, over 500 million tonnes of fly ash are released each year. Approx. $20 \%$ of total discharged fly ash, used as building materials, because fly ash possesses a pozzolanic property after lime-reaction. In the manufacturing of Portland cement concrete, fly ash serves as a supplementary cementitious material (SCM). Since, fly ash comprises fine structure and hazardous ingredients, therefore it is usually disposed in landfills, which may further pose serious threats to different ecosystems. Fly ash disposal is a global issue that has shifted to the top of the priority list. Fly ash received after its usage in effluent treatment plant is usually rich in organic content. Fly ash is presently easy to dispose of in slurry form in fly ash ponds. The increase in organic components in surface and groundwater is the most serious environmental issue caused by fly ash dumping, discharge, and disposal. Unless fly ash ponds are properly sealed, fly ashes precipitated from the air via rain tend to find their way into surface waters. However, regeneration efficiency depends upon solubility of adsorbed constituents and pressure impact on carbon's chemical structure. Additionally, the procedure becomes quite costly because of the substantial investment in high-pressure equipment. As a result of these significant limitations, a variety of regeneration strategies are currently being researched. Some of these procedures can be used in situ and have the benefit of oxidizing organic pollutants in the anode while also allowing the active adsorbing site of drained activated carbon to be recovered. Several authors have agreed that increasing the regeneration time and usage of current led to increase in regeneration efficiency [161].

Recently, researchers are focusing on improving fly ash efficiency to boost its adsorption rate through appropriate modification and regeneration procedures. The use of inexpensive, effective, and widely available fly ash as adsorbents can replace the usage of commercially supplied activated carbon for the removal of contaminants. More research is needed to better understand the process and mechanics of using low-cost adsorbent materials in order to effectively demonstrate the technology. The disposal of pollutant-laden industrial waste material is once again a major issue. If this is not executed properly, a major question such as what happens to the ash after adsorption would arise, rendering the entire study worthless because, it contains hazardous adsorbates, and it may worsen the situation more. The polluted ash can still be utilized in cement or concrete manufacture, brick manufacturing, and as a filler in road construction or for other reasons; a worthwhile valorization. As a result, more concrete study on the different ways for ensuring environmentally friendly, safe disposal and optimization of used up adsorbent portion of pollutant laden adsorbents should be undertaken. According to reviewed literature, the adsorption method is regarded as an effective treatment for removing emerging pollutants from water. It facilitates higher percentage removal efficiency. Being a physical method in nature, it does not produce by-products that might be more hazardous than the parent ones. The adsorption process, of course, is part of an integrated treatment system that takes into account a variety of parameters such as space availability for treatment facilities, waste disposal restrictions, required water quality, and capital and operational expenses. Fly ash activated carbons are prepared using industrial solid wastes. This is a sustainable renewable approach for adsorption of harmful contaminants and is of immense significance for pollution abatement and environmental management [161].

Adsorption is the process of removing metal ions from solid surfaces. Adhesion forces are formed between metal ions and mesopores for evident adsorption process. Mesoporous surfaces are also necessary for desorption processes that affect the adsorbents' regeneration and reusability. Simple cleaning through washing, steam washing, chemical treatment, or heat treatment is frequently used to accomplish this process. As the geopolymer dose, contact duration, and temperature rise, the removal efficiency improves. This means that the geopolymer's adsorption active sites do not get saturated immediately, and a steady rise in metal ion transfer onto the geopolymer's surface is seen until the equilibrium position is reached. This is owing to the geopolymers' high density of adsorptive sites. As a result, this reveals that geopolymers may be used as a wastewater purifier in bed filter systems (heavy metal getters) for real-world applications.

The majority of heavy metal cations have been considerably desorbed in acidic solutions such as $\mathrm{HCl}, \mathrm{H}_{2} \mathrm{SO}_{4}$, and $\mathrm{HNO}_{3}$ as stripping agents, implying that FA-based adsorbents may be successfully regenerated, rejuvenated, and further re-used, according to the reviewed desorption experiments. As current literature suggests that fly ash-based adsorbents for heavy metals may be successfully regenerated and re-used, thus more research and development in this area is recommended to be encouraged and enhanced [162].

\section{Future prospects}

Geopolymers are performing excellent role in heavy metal remediation from contaminated solutions. Geopolymers may be prepared as per the requirements of the specific applications using a variety of precursors 
and development conditions. Different physico-chemical modifications need more investigations for the proper use of the geopolymerized materials in treatment of real wastewaters with multi-component systems for uninterrupted operations on commercial scale. The performances of geopolymers should be optimized with the enhancement in adsorption capacities and adsorption rate. Furthermore, research on various aspects of the effects of geopolymers on human exposure must be carried out. Geopolymers are most suited for heavy metal removal from wastewater samples due to constituents of geopolymers bearing negative charge. Some more adsorbates such as anionic-based pollutants, pharmaceuticals, agricultural pollutants, dyes, pigments, radionuclides, phenolic substances and micro-pollutants should also be tested and analysed on geopolymers. Further investigations on the probable aluminosilicate sources can also be done for the bulk synthesis of geopolymers.

Hybrid, advanced, and composite geopolymers in association with nanomaterials should also be developed for better removal of impurities from polluted water. Recently, geopolymers have been used in batch experiments with one component on laboratory scales. Appropriation for treating the multicontaminants needs to be addressed and this upcoming work will not only emphasis on suitability but also the selectivity of contaminants for particular type of geopolymeric adsorbent. In the future, these investigations will assist in validating the findings on industrial wastewaters and will progress to a continuous process dealing with systems including single and multiple components. In addition, a comprehensive assessment and analysis of waste geopolymers containing aluminosilicate minerals should be conducted, and a comprehensive strategic plan should be developed to ensure that these materials are re-used, reduced, recycled, and disposed of in a productive and efficient manner. The available studies containing relevant analysis of fly ash-based geopolymers employed for heavy metal removal are very few, so this area needs to be explored with single or combination of toxic heavy metals present in aqueous solutions.

\section{Conclusions}

The significant amounts of aluminosilicate present in different types of materials would serve as a source to produce useful valuable products for various industries. Recent developments in replacing or incorporating concrete and substrates with geopolymers have paved a way to use them for removal of lethal and toxic pollutants from environmental surroundings. Current global scenario demands reduce, re-use and recycling of waste or by-products, and in this context, geopolymers are considered to be the next revolutionary engineering material.
The efficiency, stability, mechanical strength, environmental friendliness, and inexpensiveness have drawn the curiosity of the environmentalists towards the exploration of geopolymers as adsorbents in water treatment processes. Geopolymers exhibited its potential, compatibility and good performances in heavy metal remediation processes. Specific parameters such as amorphousness, surface area, surface texture, porosity, orientation, dispersion, durability, surface $\mathrm{pH}$, chemistry involved in chemical modification, immobilization of pollutants, cost efficiency, eco-friendly preparations and treatments must be tailored to harness the full potential of advantages of geopolymers. This article throws light on possible utilization of geopolymers for heavy metal removal from aqueous solutions. Several findings of different researchers showed that alkali-activated geopolymers work effectively in heavy metal removal like other adsorbents used in previous researches performed due to being amorphous in nature and porous structure. They can be extensively studied for the removal of other contaminants also. Geopolymers require improvement in adsorption rates being examined on industrial effluents containing multicomponents system for continuous operations. Finally, it is concluded that fly ash-based geopolymers offer an adequate economical method which proposes a solution for accumulated mountains of fly ash solid waste material and depollution of environmental dimensions.

\section{Acknowledgements \\ The authors would like to show gratitude to all the contributors who directly or indirectly helped us out in the preparation of this article.}

\section{Authors' contributions}

PG and GN conceived the study. PG structured the contents, wrote, and revised the full article. GN organized, edited, and formatted the manuscript. NG edited, formatted and revised the manuscript. All the authors gave input throughout the study, read and finally approved the manuscript.

Funding

No specific grant from funding agencies in the public, organization, commercial, or not-for-profit sectors.

Availability of data and materials

Not applicable.

\section{Declarations}

Ethics approval and consent to participate

Not applicable.

Consent for publication

Not applicable.

Competing interests

No conflict of interests was declared by the author(s).

\section{Author details}

${ }^{1}$ Department of Chemistry, Faculty of Engineering and Technology, SRM Institute of Science and Technology, NCR Campus, Delhi-NCR Campus, Delhi-Meerut Road, Modinagar, Ghaziabad, Uttar Pradesh 201204, India.

2Department of RTDC, Sharda University, Greater Noida, Uttar Pradesh 201306, 
India. ${ }^{3}$ Department of Chemistry, RBS Engineering Technical Campus, Bichpuri, Agra, Uttar Pradesh 283105, India.

Received: 4 March 2021 Accepted: 27 November 2021 Published online: 18 December 2021

\section{References}

1. Adamczuk A, Kolodynska D (2015) Equilibrium, thermodynamic and kinetic studies on removal of chromium, copper, zinc, and arsenic from aqueous solutions onto fly ash coated by chitosan. Chem Eng J 274:200-212. https://doi.org/10.1016/j.cej.2015.03.088

2. Da'na $E$ (2017) Adsorption of heavy metals on functionalizedmesoporous silica: a review. Microporous Mesoporous Mater 247:145-157. https://doi.org/10.1016/j.micromeso.2017.03.050

3. Alwan GM, Mehdi FA, Arazak AA, Manual N (2010) Operation and pH control of a wastewater treatment unit using labview. Eng Technol J 28(17):5525-5546

4. Futalan CM, Kan CC, Dalida ML, Pascua C, Wan MW (2011) Fixed-bed column studies on the removal of copper using chitosan immobilized on bentonite. Carbohydr Polym 83(2):697-704. https://doi.org/ 10.1016/j.carbpol.2010.08.043

5. Lü L, Chen L, Shao W, Luo F (2010) Equilibrium and kinetic modeling of $\mathrm{Pb}(\mathrm{II})$ biosorption by a chemically modified orange peel containing cyanex 272. J Chem Eng Data 55(10):4147-4153. https://doi.org/ $10.1021 /$ je1000846

6. $\mathrm{WHO}$ (2003) Arsenic in drinking-water. In: Background document for preparation of WHO guidelines for drinking-water quality (WHO/ SDE/WSH/0304/75). World Health Organization, Geneva

7. $\mathrm{WHO}$ (2003) Chromium in drinking-water. In: Background document for preparation of $\mathrm{WHO}$ guidelines for drinking drinking-water quality (WHO/SDE/WSH/0304/04). World Health Organization, Geneva

8. WHO (2003) Copper in drinking-water. In: Background document for preparation of WHO Guidelines for drinking-water quality (WHO/ SDE/WSH/0304/88). World Health Organization, Geneva

9. WHO (2003) Antimony in drinking-water. In: Background document for preparation of WHO guidelines for drinking-water quality (WHO/ SDE/WSH/0304/74). World Health Organization, Geneva

10. WHO (2003) Lead in drinking-water. In: Background document for preparation of WHO guidelines for drinking-water quality (WHO/ SDE/WSH/0304/9). World Health Organization, Geneva

11. WHO (2003) Manganese in drinking-water. In: Background document for preparation of WHO guidelines for drinking-water quality (WHO/ SDE/WSH/0304/104). World Health Organization, Geneva

12. WHO (2005) Mercury in in drinking-water. In: Background document for preparation of WHO guidelines for drinking-water quality (WHO/ SDE/WSH/0508/10). World Health Organization, Geneva

13. WHO (2003) Molybdenum in drinking-water. In: Background document for preparation of WHO guidelines for drinking-water quality (WHO/SDE/WSH/0304/11). World Health Organization, Geneva

14. WHO (2005) Nickel in drinking-water. In: Background document for preparation of $\mathrm{WHO}$ guidelines for drinking-water quality (WHO/ SDE/WSH/0508/55). World Health Organization, Geneva

15. WHO (2003) Selenium in drinking-water. In: Background document for preparation of WHO guidelines for drinking-water quality (WHO/ SDE/WSH/0304/13). World Health Organization, Geneva

16. Singh NB, Nagpal G, Agrawal S, Rachna (2018) Water purification by using adsorbents: a review. Environ Technol Innov 11:187-240. https://doi.org/10.1016/j.eti.2018.05.006

17. Ahmed MJK, Ahmaruzzaman M (2016) A review on potential usage of industrial waste materials for binding heavy metal ions from aqueous solutions. J Water Process Eng 10:39-47. https://doi.org/10.1016/j. jwpe.2016.01.014

18. Yadav S, Gupta P, Vatsa P, Singh RP (2011) Use of pyroaurite type sorbent, activated carbon and flyash in reducing cod of domestic wastewater. Enpro J 1(1):30-36

19. Guieysse B, Norvill ZN (2014) Sequential chemical-biological processes for the treatment of industrial wastewaters: review of recent progresses and critical assessment. J Hazard Mater. https://doi.org/ 10.1016/j.jhazmat.2013.12.016
20. Gupta P, Gupta S, Suman R, Gupta R, Pathak B, Singh RP (2005) Elimination of $\mathrm{Hg}$ (II) from aqueous solution using mesoporous sorbent, ceralite, activated carbon, goethite and rice husk. Environ Geochem Special Issue 8(1-2):335-339

21. Fu F, Wang Q (2011) Removal of heavy metal ions from wastewaters: a review. J Environ Manag 92(3):407-418. https://doi.org/10.1016/j. jenvman.2010.11.011

22. O'Connell DW, Birkinshaw C, O'Dwyer TF (2008) Heavy metal adsorbents prepared from the modification of cellulose: a review. Bioresour Technol 99(15):6709-6724. https://doi.org/10.1016/j.biort ech.2008.01.036

23. Zhou LC, Meng XG, Fu JW, Yang YC, Yang P, Mi C (2014) Highly efficient adsorption of chlorophenols onto chemically modified chitosan. Appl Surf Sci 292:735-741. https://doi.org/10.1016/j.apsusc.2013.12.041

24. Worch E (2012) Adsorption technology in water treatment: fundamentals, processes, and modelling. Walter de Gruyter, GmbH \& Co. K, Berlin

25. Quist-Jensen CA, Macedonio F, Drioli E (2015) Membrane technology for water production in agriculture. Desalination 364:17-32. https://doi. org/10.1016/j.desal.2015.03.001

26. Das R, Ali ME, Hamid SBA, Ramakrishna S, Chowdhury ZZ (2014) Carbon nanotube membranes for water purification: a bright future in water desalination. Desalination 336:97-109. https://doi.org/10.1016/j.desal. 2013.12.026

27. Albayati TM, Alwan GM, Mahdy OS (2017) High performance methyl orange capture on magnetic nanoporous MCM-41 prepared by incipient wetness impregnation method. Korean J Chem Eng 34(1):259-265. https://doi.org/10.1007/s11814-016-0231-2

28. Galán J, Rodríguez A, Gómez JM, Allen SJ, Walker GM (2013) Reactive dye adsorption onto a novel mesoporous carbon. Chem Eng J 219:62-68. https://doi.org/10.1016/j.cej.2012.12.073

29. Holkar CR, Jadhav AJ, Pinjari DV, Mahamuni NM, Pandit AB (2016) A critical review on textile wastewater treatments: possible approaches. J Environ Manag 182:351-366. https://doi.org/10.1016/j.jenvman.2016. 07.090

30. Badawi MA, Negm NA, Abou Kana MTH, Hefni HH, Abdel Moneem MM (2017) Adsorption of aluminum and lead from wastewater by chitosantannic acid modified biopolymers: isotherms kinetics thermodynamics and process mechanism. Int J Biol Macromol 99:465-476. https://doi. org/10.1016/j.ijbiomac.2017.03.003

31. Bhatnagar A, Sillanpaa M, Witek-Krowiak A (2015) Agricultural waste peels as versatile biomass for water purification-a review. Chem Eng J 270:244-271. https://doi.org/10.1016/J.CEJ.2015.01.135

32. Raval NP, Shah PU, Shah NK (2016) Adsorptive removal of nickel (II) ions from aqueous environment: a review. J Environ Manage 179:1-20. https://doi.org/10.1016/j.jenvman.2016.04.045

33. Yu S, Wang X, Pang H, Zhang R, Song W, Fu D, Hayat T, Wang X (2018) Boron nitride-based materials for the removal of pollutants from aqueous solutions: a review. Chem Eng J 333:343-360. https://doi.org/10. 1016/j.cej.2017.09.163

34. Yu S, Wang X, Ai Y, Tan X, Hayat T, Hu W, Wang X (2016) Experimental and theoretical studies on competitive adsorption of aromatic compounds on reduced graphene oxides. J Mater Chem A 4:5654-5662. https://doi.org/10.1039/C6TA00890A

35. Yu JG, Zhao XH, Yang H, Chen XH, Yang Q, Yu LY, Jiang JH, Chen XQ (2014) Aqueous adsorption and removal of organic contaminants by carbon nanotubes. Sci Total Environ 482:241-251. https://doi.org/10. 1016/j.scitotenv.2014.02.129

36. Zhang Y, Ou H, Liu H, Ke Y, Zhang W, Liao G, Wang D (2018) Polyimidebased carbon nanofibers: a versatile adsorbent for highly efficient removals of chlorophenols dyes and antibiotics. Colloids Surf A 537:92-101. https://doi.org/10.1016/j.colsurfa.2017.10.014

37. Ahmad T, Danish M (2018) Prospects of banana waste utilization in wastewater treatment: a review. J Environ Manag 206:330-348. https:// doi.org/10.1016/j.jenvman.2017.10.061

38. Olu-Owolabi Bl, Alabi AH, Diagboya PNE, Unuabonah El, During Rolf A (2017) Adsorptive removal of 2,4,6-trichlorophenol in aqueous solution using calcined kaolinite-biomass composites. J Environ Manage 192:94-99. https://doi.org/10.1016/j.jenvman.2017.01.055

39. Masoumi A, Hemmati K, Ghaemy M (2016) Low-cost nanoparticles sorbent from modified rice husk and a copolymer for efficient removal 
of Pb(II) and crystal violet from water. Chemosphere 146:253-262. https://doi.org/10.1016/j.chemosphere.2015.12.017

40. Sharma VK, McDonald TJ, Kim H, Garg VK (2015) Magnetic graphenecarbon nanotube iron nanocomposites as adsorbents and antibacterial agents for water purification. Adv Colloid Interface Sci 225:229-240. https://doi.org/10.1016/j.cis.2015.10.006

41. Bharath G, Alhseinat E, Ponpandian N, Khan MA, Siddiqui MR, Ahmed F, Alsharaeh EH (2017) Development of adsorption and electrosorption techniques for removal of organic and inorganic pollutants from wastewater using novel magnetite/porous graphene-based nanocomposites. Sep Purif Technol 188:206-218. https://doi.org/10.1016/j.seppur. 2017.07.024

42. Wang $X$, Yu S, Jin J, Wang H, Alharbi NS, Alsaedi A, Hayat T, Wang X (2016) Application of graphene oxides and graphene oxide-based nanomaterials in radionuclide removal from aqueous solutions. Sci Bull 61(20):1583-1593. https://doi.org/10.1007/s11434-016-1168-x

43. Dubey S, Banerjee S, Upadhyay SN, Sharma YC (2017) Application of common nano-materials for removal of selected metallic species from water and wastewaters: a critical review. J Mol Liq 240:656-677. https:// doi.org/10.1016/j.molliq.2017.05.107

44. Pandey S (2017) A comprehensive review on recent developments in bentonite-based materials used as adsorbents for wastewater treatment. J Mol Liq 241:1091-1113. https://doi.org/10.1016/j.molliq.2017. 06.115

45. Reddy DHK, Yun YS (2016) Spinel ferrite magnetic adsorbents: alternative future materials for water purification. Coord Chem Rev 315:90111. https://doi.org/10.1016/j.ccr.2016.01.012

46. Lin S, Yang Y, Chen G, Chen X, Zhang W, Xu M, Liu L, Lin K (2017) Study on the influence of thiolation on the adsorption and magnetic recovery of superparamagnetic nano adsorbents for $\mathrm{Cd}^{2+}$ removal. Appl Surf Sci 425:141-147. https://doi.org/10.1016/j.apsusc.2017.06.282

47. Adeleye AS, Conway JR, Garner K, Huang Y, Su Y, Keller AA (2016) Engineered nanomaterials for water treatment and remediation: costs, benefits, and applicability. Chem Eng J 286:640-662. https://doi.org/10. 1016/j.cej.2015.10.105

48. Luo T, Qu L, Hou X, Liu X, Wang S, Wu Y (2017) Preparation of 3-dimensional flower-like $\mathrm{NiFe}_{2} \mathrm{O}_{4}$ with enhanced adsorptive performance for water contaminants. J Alloys Compd 727:484-490. https://doi.org/10. 1016/j.jallcom.2017.07.234

49. Mittala H, Maitya A, Ray SS (2016) Gum karaya based hydrogel nanocomposites for the effective removal of cationic dyes from aqueous solutions. Appl Surf Sci 364:917-930. https://doi.org/10.1016/j.apsusc. 2015.12.241

50. Kyzas GZ, Matis KA (2015) Nanoadsorbents for pollutants removal: a review. J Mol Liq 203:159-168. https://doi.org/10.1016/j.molliq.2015.01. 004

51. Kyzas GZ, Bikiaris DN (2015) Recent modifications of chitosan for adsorption application: a critical and systematic review. Mar Drugs 13(1):312-337. https://doi.org/10.3390/md13010312

52. Georgieva VG, Tavlieva MP, Genieva SD, Vlaev LT (2015) Adsorption kinetics of $\mathrm{Cr}(\mathrm{VI})$ ions from aqueous solutions onto black rice husk ash. $J$ Mol Liq 208:219-226. https://doi.org/10.1016/j.molliq.2015.04.047

53. Gupta VK, Ali I (2004) Removal of lead and chromium from wastewater using bagasse fly ash-a sugar industry waste. J Colloid Interface Sci 271(2):321-328. https://doi.org/10.1016/j.jcis.2003.11.007

54. Gupta VK, Carrott PJM, Ribeiro Carrott MML, Suhas, (2009) Low-cost adsorbents: growing approach to wastewater treatment-a review. Crit Rev Environ Sci Technol 39:783-842. https://doi.org/10.1080/10643 380801977610

55. He P, Zhang XB, Peng XL, Wu J, Jiang XM (2016) Effect of fly ash composition on the retention of mercury in coal-combustion flue gas. Fuel Process Technol 142:6-12. https://doi.org/10.1016/j.fuproc.2015.09.023

56. Ward CR, French D (2006) Determination of glass content and estimation of glass composition in fly ash using quantitative X-ray diffractometry. Fuel 85(16):2268-2277. https://doi.org/10.1016/j.fuel.2005.12.026

57. Ahmaruzzaman M (2010) A review on the utilization of fly ash. Prog Energy Combust Sci 3:327-363. https://doi.org/10.1016/j.pecs.2009.11. 003

58. Petcherdchoo A (2015) Repairs by fly ash concrete to extend service life of chloride exposed concrete structures considering environmental impacts. Constr Build Mater 98:799-809. https://doi.org/10.1016/j. conbuildmat.2015.08.120

59. Šiler P, Bayer P, Sehnal T, Kolárová I, Opravil T, Šoukal F (2015) Effects of high temperature fly ash and fluidized bed combustion ash on the hydration of Portland cement. Constr Build Mater 78:181-188. https:// doi.org/10.1016/j.conbuildmat.2015.01.032

60. Blissett RS, Rowson NA (2012) A review of the multi-component utilization of coal fly ash. Fuel 97:1-23. https://doi.org/10.1016/j.fuel.2012.03. 024

61. Davidovits J (1991) Geopolymers: inorganic polymeric new materials. J Therm Anal 37:1633-1656. https://doi.org/10.1007/BF01912193

62. Duxson P, Fernandez-Jimenez A, Provis JL, Lukey GC, Palomo A, Van Deventer JSJ (2007) Geopolymer technology: the current state of the art. J Mater Sci 42:2917-2933. https://doi.org/10.1007/ s10853-006-0637-z

63. Hwang CL, Huynh TP (2015) Effect of alkali-activator and rice husk ash content on strength development of fly ash and residual rice husk ash-based geopolymers. Constr Build Mater 101:1-9. https:// doi.org/10.1016/j.conbuildmat.2015.10.025

64. Xie TY, Ozbakkaloglu T (2015) Behavior of low-calcium fly and bottom ash-based geopolymer concrete cured at ambient temperature. Ceram Int 41(4):5945-5958. https://doi.org/10.1016/j.ceramint.2015. 01.031

65. Diaz El, Allouche EN, Eklund S (2010) Factors affecting the suitability of fly ash as source material for geopolymers. Fuel 89(5):992-996. https://doi.org/10.1016/j.fuel.2009.09.012

66. Junaid MT, Kayali O, Khennane A, Black J (2015) A mix design procedure for low calcium alkali activated fly ash-based concretes. Constr Build Mater 79:301-310. https://doi.org/10.1016/j.conbuildmat.2015. 01.048

67. Yao ZT, Ji XS, Sarker PK, Tang JH, Ge LQ, Xia MS, Xi YQ (2015) A comprehensive review on the applications of coal fly ash. Earth Sci Rev 141:105-121. https://doi.org/10.1016/j.earscirev.2014.11.016

68. Cheng TW, Lee ML, Ko MS, Ueng TH, Yang SF (2012) The heavy metal adsorption characteristics on metakaolin-based geopolymer. App Clay Sci 56:90-96. https://doi.org/10.1016/j.clay.2011.11.027

69. Zhang Y, Liu L (2013) Fly ash-based geopolymer as a novel photocatalyst for degradation of dye from wastewater. Particuology 11:353-358. https://doi.org/10.1016/j.partic.2012.10.007

70. Davidovits J (1989) Geopolymers and geopolymeric new materials. J Therm Anal 35(2):429-441. https://doi.org/10.1007/BF01904446

71. Davidovits J (1994) Geopolymers: inorganic polymeric new materials. J Mater Educ 16:91-139

72. Davidovits J (2008) Geopolymer chemistry and applications, 3rd printing. Institute Geopolymer, Saint-Quentin

73. Sumesh M, Alengaram UJ, Jumaat MZ, Mo KH, Alnahhal MF (2017) Incorporation of nanomaterials in cement composite and geopolymer based paste and mortar-a review. Constr Build Mater 148:62-84. https://doi.org/10.1016/j.conbuildmat.2017.04.206

74. Emdadi Z, Asim N, Amin MH, Yarmo MA, Maleki A, Azizi M, Sopian K (2017) Development of green geopolymer using agricultural and industrial waste materials with high water absorbency. Appl Sci 7(5):514. https://doi.org/10.3390/app7050514

75. Sun S, Lin J, Zhang P, Fang L, Ma R, Quan Z, Song X (2018) Geopolymer synthetized from sludge residue pretreated by the wet alkalinizing method: compressive strength and immobilization efficiency of heavy metal. Constr Build Mater 170:619-626. https://doi.org/10.1016/j.conbu ildmat.2018.03.068

76. Asim N, Alghoul M, Mohammad M, Amin MH, Akhtaruzzaman M, Amin N, Sopian K (2019) Emerging sustainable solutions for depollution: geopolymers. Constr Build Mater 199:540-548. https://doi.org/10.1016/j. conbuildmat.2018.12.043

77. Ariffin N, Abdullah MMAB, Zainol RRMA, Murshed MF (2017) Geopolymer as an adsorbent of heavy metal: a review. In: AIP conference proceedings 1885. AlP Publishing. https://doi.org/10.1063/1.5002224

78. Lee S, Van Riessen A, Chon CM, Kang NH, Jou HT, Kim YJ (2016) Impact of activator type on the immobilisation of lead in fly ash-based geopolymer. J Hazard Mater 305:59-66. https://doi.org/10.1016/j.jhazmat. 2015.11 .023

79. Li W, Dong H, Yu H, Wang D, Yu H (2018) Global characteristics and trends of research on ceramic membranes from 1998 to (2016): based 
on bibliometric analysis combined with information visualization analysis. Ceram Int 44:6926-6934. https://doi.org/10.1016/J.CERAMINT.2018. 01.121

80. Liew YM, Heah CY, Mohd Mustafa AB, Kamarudin H (2016) Structure and properties of clay-based geopolymer cements: a review. Prog Mater Sci 83:595-629. https://doi.org/10.1016/j.pmatsci.2016.08.002

81. Zhang ZH, Zhu HJ, Zhou CH, Wang H (2016) Geopolymer from kaolin in China: an overview. Appl Clay Sci 119:31-41. https://doi.org/10.1016/j. clay.2015.04.023

82. Siyal AA, Shamsuddin MR, Khan MI, Rabat NE, Zulfiqar M, Man Z, Siame J, Azizli KA (2018) A review on geopolymers as emerging materials for the adsorption of heavy metals and dyes. J Environ Manage 224:327339. https://doi.org/10.1016/j.jenvman.2018.07.046

83. Abdullah MM, Hussin K, Bnhussain M, Ismail KN, Ibrahim WM (2011) Mechanism and chemical reaction of fly ash geopolymer cement-a review. Int J Pure Appl Sci Technol 6:35-44

84. Singh NB (2018) Fly ash-based geopolymer binder: a future construction material. Minerals 8(7):299. https://doi.org/10.3390/min8070299

85. Duan P, Yan CJ, Luo WJ, Zhou W (2016) A novel surface waterproof geopolymer derived from metakaolin by hydrophobic modification. Mater Lett 164:172-175. https://doi.org/10.1016/j.matlet.2015.11.006

86. Qi G, Lei X, Li L, Yuan C, Sun Y, Chen J, Chen J, Wang Y, Hao J (2015) Preparation and evaluation of a mesoporous calcium-silicate material (MCSM) from coal fly ash for removal of Co(II) from wastewater. Chem Eng J 279:777-787. https://doi.org/10.1016/j.cej.2015.05.077

87. Al-Harahsheh MS, Al-Zboon K, Al-Makhadmeh L, Hararah M, Mahasneh M (2015) Fly ash based geopolymer for heavy metal removal: a case study on copper removal. J Environ Chem Eng 3:1669-1677. https://doi.org/10.1016/j.jece.2015.06.005

88. Hosseini AsI SM, Ahmadi M, Ghiasvand M, Tardast A, Katal R (2013) Artificial neural network (ANN) approach for modeling of $\mathrm{Cr}(\mathrm{VI})$ adsorption from aqueous solution by zeolite prepared from raw fly ash (ZFA). J Ind Eng Chem 19:1044-1055. https://doi.org/10.1016/j. jiec.2012.12.001

89. Shyam R, Puri JK, Kaur H, Amutha R, Kapila A (2013) Single and binary adsorption of heavy metals on fly ash samples from aqueous solution. J Mol Liq 178:31-36. https://doi.org/10.1016/j.molliq.2012.10. 031

90. Onutai S, Kobayashi T, Thavorniti P, Jiemsirilers S (2019) Porous fly ash-based geopolymer composite fiber as an adsorbent for removal of heavy metal ions from wastewater. Mater Lett 236:30-33. https://doi. org/10.1016/j.matlet.2018.10.035

91. Asl SMH, Javadian H, Khavarpour M, Belviso C, Taghavi M, Maghsudi M (2019) Porous adsorbents derived from coal fly ash as cost-effective and environmentally-friendly sources of aluminosilicate for sequestration of aqueous and gaseous pollutants: a review. J Clean Prod 208:1131-1147. https://doi.org/10.1016/j.jclepro.2018.10.186

92. Barbosa VFF, Mackenzie KJD (2003) Thermal behaviour of inorganic geopolymers and composites derived from sodium polysalate. Mater Res Bull 38(2):319-331

93. Wu HC, Sun P (2007) New building materials from fly ash-based lightweight inorganic polymer. Constr Build Mater 21(1):211-217. https:// doi.org/10.1016/j.conbuildmat.2005.06.052

94. Ji Z, Pei Y (2019) Bibliographic and visualized analysis of geopolymer research and its application in heavy metal immobilization: a review. J Environ Manage 231:256-267. https://doi.org/10.1016/j.jenvman.2018. 10.041

95. Sanchez F, Sobolev K (2010) Nanotechnology in concrete-a review. Constr Build Mater 24(11):2060-2071. https://doi.org/10.1016/j.conbu ildmat.2010.03.014

96. Alzeer MIM, MacKenzie KJD, Keyzers RA (2016) Porous aluminosilicate inorganic polymers (geopolymers): a new class of environmentally benign heterogeneous solid acid catalysts. Appl Catal A 524:173-181. https://doi.org/10.1016/.apcata.2016.06.024

97. Naskar S, Chakraborty AK (2016) Effect of nano materials in geopolymer concrete. Perspect Sci 8:273-275. https://doi.org/10.1016/j.pisc.2016.04. 049

98. Purbasari A, Ariyanti D, Sumardiono S (2020) Preparation and application of fly ash-based geopolymer for heavy metal removal. In: AIP conference proceedings, vol 2197, p 050006. AlP Publishing LLC. https:// doi.org/10.1063/1.5140918
99. Sival AA, Azizili KA, Ismail L, Zakaria Khan MI (2016) Suitability of Malaysian fly ash for geopolymer synthesis. Adv Mater Res 1133:201-205. https://doi.org/10.4028/www.scientific.net/AMR.1133.201

100. Nath SK, Maitra S, Mukherjee S, Kumar S (2016) Microstructural and morphological evolution of fly ash based geopolymers. Constr Build Mater 111:758-765. https://doi.org/10.1016/j.conbuildmat.2016.02.106

101. Mužek MN, Svilović S, Zelić J (2014) Fly ash-based geopolymeric adsorbent for copper ion removal from wastewater. Desalin Water Treat 52(13-15):2519-2526. https://doi.org/10.1080/19443994.2013.792015

102. Hongqiang M, Hongyu C, Jinliang H, Jieya G, Wei L (2020) Citespacebased visualization analysis on mappings of alkali-activated cementitious materials in the field of engineering research case study. Constr Mater. https://doi.org/10.1016/j.cscm.2020.e00350

103. Bai C, Colombo P (2018) Processing, properties, and applications of highly porous geopolymers: a review. Ceram Int 44(14):16103-16118. https://doi.org/10.1016/j.ceramint.2018.05.219

104. Darmayanti L, Kadja GT, Notodarmojo S, Damanhuri E, Mukti RR (2019) Structural alteration within fly ash-based geopolymers governing the adsorption of $\mathrm{Cu}^{2+}$ from aqueous environment: effect of alkali activation. J Hazard Mater 377:305-314. https://doi.org/10.1016/j.jhazmat. 2019.05.086

105. Liu Y, Yan C, Zhang Z, Wang H, Zhou S, Zhou W (2016) A comparative study on fly ash geopolymer and faujasite block for $\mathrm{Pb}$ removal from aqueous solution. Fuel 185:181-189. https://doi.org/10.1016/j.fuel.2016. 07.116

106. Rasaki SA, Bingxue Z, Guarecuco R, Thomas T, Minghui Y (2019) Geopolymer for use in heavy metals adsorption and advanced oxidative processes: a critical review. J Clean Prod 213:42-58. https://doi.org/10. 1016/j.jclepro.2018.12.145

107. Wang S, Li L, Zhu Z (2007) Solid-state conversion of fly ash to effective adsorbents for Cu removal from wastewater. J Hazard Mater 139(2):254-259. https://doi.org/10.1016/j.jhazmat.2006.06.018

108. Al-Zboon K, Al-Harahsheh MS, Hani FB (2011) Fly ash-based geopolymer for $\mathrm{Pb}$ removal from aqueous solution. J Hazard Mater 188(1):414421. https://doi.org/10.1016/j.jhazmat.2011.01.133

109. Javadian H, Ghorbani F, Tayebi HA, Asl SMH (2015) Study of the adsorption of $\mathrm{Cd}(\mathrm{II})$ from aqueous solution using zeolite-based geopolymer synthesized from coal fly ash; kinetic isotherm and thermodynamic studies. Arab J Chem 8(6):837-849. https://doi.org/10.1016/j.arabjc. 2013.02.018

110. Yan C, Guo L, Ren D, Duan P (2019) Novel composites based on geopolymer for removal of Pb (II). Mater Lett 239:192-195. https://doi.org/ 10.1016/j.matlet.2018.12.105

111. Chen X, Guo Y, Ding S, Zhang H, Xia F, Wang J, Zhou M (2019) Utilization of red mud in geopolymer-based pervious concrete with function of adsorption of heavy metal. Ions J Clean Prod 207:789-800. https://doi. org/10.1016/j.jclepro.2018.09.263

112. Rożek P, Król M, Mozgawa W (2019) Geopolymer-zeolite composites: a review. J Clean Prod 230:557-579. https://doi.org/10.1016/j.jclepro. 2019.05.152

113. Kara I, Tunc D, Sayin F, Akar ST (2018) Study on the performance of metakaolin based geopolymer for Mn (II) and Co (II) removal. Appl Clay Sci 161:184-193. https://doi.org/10.1016/j.clay.2018.04.027

114. Panda L, Rath SS, Rao DS, Nayak BB, Das B, Misra PK (2018) Thorough understanding of the kinetics and mechanism of heavy metal adsorption onto a pyrophyllite mine waste based geopolymer. J Mol Liq 263:428-441. https://doi.org/10.1016/j.molliq.2018.05.016

115. Singhal A, Gangwar BP, Gayathry JM (2017) CTAB modified large surface area nanoporous geopolymer with high adsorption capacity for copper ion removal. Appl Clay Sci 150:106-114. https://doi.org/10.1016/j.clay. 2017.09.013

116. Naghsh M, Shams K (2017) Synthesis of a kaolin-based geopolymer using a novel fusion method and its application in effective water softening. Appl Clay Sci 146:238-245. https://doi.org/10.1016/j.clay.2017. 06.008

117. Lee N, Khalid HR, Lee H (2017) Adsorption characteristics of cesium onto mesoporous geopolymers containing nano-crystalline zeolites. Microporous Mesoporous Mater 242:238-244. https://doi.org/10.1016/j. micromeso.2017.01.030

118. Kara I, Yilmazer D, Akar ST (2017) Metakaolin based geopolymer as an effective adsorbent for adsorption of zinc (II) and nickel (II) ions from 
aqueous solutions. Appl Clay Sci 139:54-63. https://doi.org/10.1016/j. clay.2017.01.008

119. Sarkar C, Basu JK, Samanta AN (2017) Removal of $\mathrm{Ni}^{2+}$ ion from wastewater by geopolymeric adsorbent derived from LD slag. J Water Process Eng 17:237-244. https://doi.org/10.1016/j.jwpe.2017.04.012

120. Ge Y, Cui X, Liao C, Li Z (2017) Facile fabrication of green geopolymer/ alginate hybrid spheres for efficient removal of $\mathrm{Cu}$ (II) in water: batch and column studies. Chem Eng J 311:126-134. https://doi.org/10. 1016/j.cej.2016.11.079

121. Novais RM, Buruberri L, Seabra M, Labrincha J (2016) Novel porous fly-ash containing geopolymer monoliths for lead adsorption from wastewaters. J Hazard Mater 318:631-640. https://doi.org/10.1016/j. jhazmat.2016.07.059

122. Andrejkovičová S, Sudagar A, Rocha J, Patinha C, Hajjaji W, da Silva EF, Velosa A, Rocha F (2016) The effect of natural zeolite on microstructure. Mechanical and heavy metals adsorption properties of metakaolin based geopolymers. Appl Clay Sci 126:141-152. https://doi.org/10. 1016/i.clay.2016.03.009

123. Tang Q, Ge YY, Wang KT, He Y, Cui XM (2015) Preparation and characterization of porous metakaolin-based inorganic polymer spheres as an adsorbent. Mater Des 88:1244-1249. https://doi.org/10.1016/j.matdes. 2015.09.126

124. Medpelli D, Sandoval R, Sherrill L, Hristovski K, Seo DK (2015) Iron oxidemodified nanoporous geopolymers for arsenic removal from ground water. Resour-Effic Technol 1(1):19-27. https://doi.org/10.1016/j.reffit. 2015.06.007

125. Ge Y, Yuan Y, Wang K, He Y, Cui X (2015) Preparation of geopolymerbased inorganic membrane for removing $\mathrm{Ni}^{2+}$ from wastewater. J Hazard Mater 299:711-718. https://doi.org/10.1016/j.jhazmat.2015.08. 006

126. López FJ, Sugita S, Tagaya M, Kobayashi T (2014) Metakaolin-based geopolymers for targeted adsorbents to heavy metal ion separation. J Mater Sci Chem Eng 2(07):16. https://doi.org/10.4236/msce.2014.27002

127. Chen YL, Tong YY, Pan RW, Tang J (2013) The research on adsorption behaviors and mechanisms of geopolymers on $\mathrm{Sr}^{2+}, \mathrm{Co}^{2+}$, and $\mathrm{Cs}^{+}$. Adv Mater Res 704:313-318. https://doi.org/10.4028/www.scientific net/AMR.704.313

128. Yu Z, Song W, Li J, Li Q (2020) Improved simultaneous adsorption of Cu (II) and $\mathrm{Cr}$ (VI) of organic modified metakaolin-based geopolymer. Arab J Chem 13(3):4811-4823. https://doi.org/10.1016/j.arabjc.2020.01.001

129. Ge Y, Cui X, Kong Y, Li Z, He Y, Zhou Q (2015) Porous geopolymeric spheres for removal of $\mathrm{Cu}$ (II) from aqueous solution: synthesis and evaluation. J Hazard Mater 283:244-251. https://doi.org/10.1016/j. jhazmat.2014.09.038

130. Luukkonen T, Runtti H, Niskanen M, Tolonen ET, Sarkkinen M, Kemppainen K, Rämö J, Lassi U (2016) Simultaneous removal of Ni(II), As(III), and $\mathrm{Sb}$ (III) from spiked mine effluent with metakaolin and blastfurnace-slag geopolymers. J Environ Manage 166:579-588. https://doi. org/10.1016/j.jenvman.2015.11.007

131. Luukkonen T, Tolonen ET, Runtti H, Kemppainen K, Perämäki P, Rämö J, Lassi U (2017) Optimization of the metakaolin geopolymer preparation for maximized ammonium adsorption capacity. J Mater Sci 52(16):9363-9376. https://doi.org/10.1007/s10853-017-1156-9

132. Apak R, Tütem E, Hügül M, Hizal J (1998) Heavy metal cation retention by unconventional sorbents (red muds and fly ashes). Water Res 32(2):430-440. https://doi.org/10.1016/S0043-1354(97)00204-2

133. Tofighy MA, Mohammadi T (2011) Adsorption of divalent heavy metal ions from water using carbon nanotube sheets. J Hazard Mater 185(1):140-147. https://doi.org/10.1016/j.jhazmat.2010.09.008

134. Demiral H, Güngör C (2016) Adsorption of copper (II) from aqueous solutions on activated carbon prepared from grape bagasse. J Clean Prod 124:103-113. https://doi.org/10.1016/j.jclepro.2016.02.084

135. Boddu VM, Abburi K, Randolph AJ, Smith ED (2008) Removal of copper (II) and nickel (II) ions from aqueous solutions by a composite chitosan biosorbent. Separ Sci Technol 43(6):1365-1381. https://doi.org/10.1080/ 01496390801940762

136. Gönen F, Serin DS (2012) Adsorption study on orange peel: removal of $\mathrm{Ni}$ (II) ions from aqueous solution. Afr J Biotechnol 11(5):1250-1258. https://doi.org/10.5897/AJB11.1753

137. Alandis N, Aldayel O, Mekhemer W, Hefne J, Jokhab H (2010) Thermodynamic and kinetic studies for the adsorption of Fe (III) and Ni (II) ions from aqueous solution using natural bentonite. J Dispers Sci Technol 31(11):1526-1534. https://doi.org/10.1080/01932690903294097

138. Kang S-J, Egashira K, Yoshida A (1998) Transformation of a low-grade Korean natural zeolite to high cation exchanger by hydrothermal reaction with or without fusion with sodium hydroxide. Appl Clay Sci 13(2):117-135. https://doi.org/10.1016/S0169-1317(98)00019-2

139. Zhang M, Zhang H, Xu D, Han L, Niu D, Tian B, Zhang J, Zhang L, Wu W (2011) Removal of ammonium from aqueous solutions using zeolite synthesized from fly ash by a fusion method. Desalination 271(1):111121. https://doi.org/10.1016/j.desal.2010.12.021

140. Mellah A, Chegrouche S (1997) The removal of zinc from aqueous solutions by natural bentonite. Water Res 31(3):621-629. https://doi.org/10. 1016/S0043-1354(96)00294-1

141. Amuda O, Giwa A, Bello I (2007) Removal of heavy metal from industrial wastewater using modified activated coconut shell carbon. Biochem Eng J 36(2):174-181. https://doi.org/10.1016/j.bej.2007.02.013

142. Tang Q, Wang K, Yaseen M, Tong Z, Cui X (2018) Synthesis of highly efficient porous inorganic polymer microspheres for the adsorptive removal of $\mathrm{Pb}^{2+}$ from wastewater. J Clean Prod 193:351-362. https:// doi.org/10.1016/j.jclepro.2018.05.094

143. Bektaş N, Ağım BA, Kara S (2004) Kinetic and equilibrium studies in removing lead ions from aqueous solutions by natural sepiolite. J Hazard Mater 112(1):115-122. https://doi.org/10.1016/j.jhazmat.2004. 04.015

144. Jalali R, Ghafourian H, Asef Y, Davarpanah S, Sepehr S (2002) Removal and recovery of lead using nonliving biomass of marine algae. J Hazard Mater 92(3):253-262. https://doi.org/10.1016/S0304-3894(02)00021-3

145. Alamudy HA, Cho K (2018) Selective adsorption of cesium from an aqueous solution by a montmorillonite-prussian blue hybrid. Chem Eng J 349:595-602. https://doi.org/10.1016/j.cej.2018.05.137

146. Khandaker S, Toyohara Y, Kamida S, Kuba T (2018) Effective removal of cesium from wastewater solutions using an innovative low-cost adsorbent developed from sewage sludge molten slag. J Environ Manag 222:304-315. https://doi.org/10.1016/j.jenvman.2018.05.059

147. Khandaker S, Kuba T, Kamida S, Uchikawa Y (2017) Adsorption of cesium from aqueous solution by raw and concentrated nitric acid-modified bamboo charcoal. J Environ Chem Eng 5(2):1456-1464. https://doi.org/ 10.1016/j.jece.2017.02.014

148. Shamsuddin RM, Verbeek CJ, Lay MC (2014) Producing protein intercalated bentonite-equilibrium kinetics and physical properties of gelatinbentonite system. App Clay Sci 87:52-60. https://doi.org/10.1016/j.clay. 2013.11 .023

149. Liu M, Hou LA, Xi B, Zhao Y, Xia X (2013) Synthesis, characterization, and mercury adsorption properties of hybrid mesoporous aluminosilicate sieve prepared with fly ash. Appl Surf Sci 273:706-716. https://doi.org/ 10.1016/j.apsusc.2013.02.116

150. Onutai S, Kobayashi T, Thavorniti P, Jiemsirilers S (2018) Removal of $\mathrm{Pb}^{2+}$ $\mathrm{Cu}^{2+}, \mathrm{Ni}^{2+}, \mathrm{Cd}^{2+}$ from wastewater using fly ash based geopolymer as an adsorbent. Key Eng Mater 773:373-378. https://doi.org/10.4028/ www.scientific.net/KEM.773.373

151. Gönder Z, Vergili I, Kaya Y, Barlas H (2010) Adsorption of cationic and anionic surfactants onto organic polymer resin Lewatit VPOC 1064 MD PH. Environ Geochem Health 32(4):267-273. https://doi.org/10.1007/ s10653-010-9297-7

152. Barbosa TR, Foletto EL, Dotto GL, Jahn SL (2018) Preparation of mesoporous geopolymer using metakaolin and rice husk ash as synthesis precursors and its use as potential adsorbent to remove organic dye from aqueous solutions. Ceram Int 44(1):416-423. https://doi.org/ 10.1016/j.ceramint.2017.09.193

153. Sitarz-Palczak E, Kalembkiewicz J (2012) Study of remediation of soil contaminated with heavy metals by coal fly ash. J Environ Prot 3(10):1373-1383. https://doi.org/10.4236/jep.2012.310156

154. Mishra A, Tripathi BD (2008) Utilization of fly ash in adsorption of heavy metals from wastewater. Toxicol Environ Chem 90(6):1091-1097. https://doi.org/10.1080/02772240801936786

155. Ramesh A, Kozinski JA (2001) Investigations of ash topography/morphology and their relationship with heavy metals leachability. Environ Pollut 111:255-262

156. Khanra S, Mallick D (1998) Studies on the phase mineralogy and leaching characteristics of coal fly ash. Water Air Soil Pollut 10:251-275. https://doi.org/10.1023/A:1004947519170 
157. Paul M, Seferinoglu M, Aycrk GA, Sandstrom AK, Smith M, Paul J (2006) Acid leaching of ash and coal: time dependence and trace element occurrences. Int J Miner Process 79(1):27-41. https://doi.org/10.1016/j. minpro.2005.11.008

158. Kim AG (2006) The effect of alkalinity of Class F PC fly ash on metal release. Fuel 85(10-11):1403-1410. https://doi.org/10.1016/j.fuel.2005. 11.023

159. Agrawal M, Modi A, Satvat PS, Batra V (2016) Heavy metal toxicity of fly ash exposed to acidic environments. Int J Commun Sci Technol 2(1):11-17

160. Temuujina J, Minjigmaaa A, Bayarzula U, Kimb DS, Leeb S, Leeb HJ, Ruescherc CH, Mackenzied KJD (2017) Properties of geopolymer binders prepared from milled pond ash. Mater Constr 67(328):12-30. https:// doi.org/10.3989/mc.2017.07716

161. Adegoke KA, Oyewole RO, Lasisi BM, Bello OS (2017) Abatement of organic pollutants using fly ash based adsorbents. Water Sci Technol 76(10):2580-2592. https://doi.org/10.2166/wst.2017.437

162. Aigbe UO, Ukhurebor KE, Onyancha RB, Osibote OA, Darmokoesoemo H, Kusuma HS (2021) Fly ash-based adsorbent for adsorption of heavy metals and dyes from aqueous solution: a review. J Mater Res Technol 14:2751-2774. https://doi.org/10.1016/j.jmrt.2021.07.140

\section{Publisher's Note}

Springer Nature remains neutral with regard to jurisdictional claims in published maps and institutional affiliations.

\section{Submit your manuscript to a SpringerOpen ${ }^{\odot}$ journal and benefit from:}

- Convenient online submission

- Rigorous peer review

- Open access: articles freely available online

- High visibility within the field

- Retaining the copyright to your article

Submit your next manuscript at $\boldsymbol{\text { springeropen.com }}$ 